\title{
Plasma potential probes for hot plasmas
}

\section{A review and some news}

Codrina Ionita ${ }^{1}$, Bernd Sebastian Schneider ${ }^{1}$, Stefan Costea $^{1}$, Ovidiu Vasilovici ${ }^{1}$, Jernej Kovačič ${ }^{2}$, Tomaz Gyergyek ${ }^{2,3}$, Volker Naulin ${ }^{4}$, Jens Juul Rasmussen ${ }^{4}$, Nicola Vianello ${ }^{5}$, Monica Spolaore ${ }^{5}$, Ronald Stärz ${ }^{1,6}$, and Roman Schrittwieser ${ }^{1, a}$

${ }^{1}$ Institute for Ion Physics and Applied Physics, University of Innsbruck, Innsbruck, Austria

2 Reactor Physics Department, Jožef Stefan Institute, Ljubljana, Slovenia

${ }^{3}$ Faculty of Electrical Engineering, University of Ljubljana, Ljubljana, Slovenia

${ }^{4}$ Department of Physics, Technical University of Denmark, Kgs. Lyngby, Denmark

${ }^{5}$ Consorzio RFX, Padua, Italy

${ }^{6}$ Mechatronic Department, Management Center Innsbruck, 6020 Innsbruck, Austria

Received 25 September 2018 / Received in final form 29 December 2018

Published online 9 April 2019

(C) The Author(s) 2019. This article is published with open access at Springerlink.com

\begin{abstract}
Plasma probes are well established diagnostic tools. They are not complicated, relatively easy to construct and to handle. The easiest and fastest accessible parameter is their floating potential. However, the floating potential of a cold probe is not very significant. Much more important and relevant is the plasma potential. But in most types of plasmas, consisting mainly of electrons and only positive ions, the floating potential is more negative than the plasma potential by a factor proportional to the electron temperature. Obviously this is due to the much higher mobility of the electrons. We present a review on probes whose floating potential is close to or ideally equal to the plasma potential. Such probes we name Plasma Potential Probes (PPP) and they can either be Electron Emissive Probes (EEP) or so-called Electron Screening Probes (EPS). These probes make it possible to measure the plasma potential directly and thus with high temporal resolution. An EEP compensates the plasma electron current by an electron emission current from the probe into the plasma, thereby rendering the current-voltage characteristic symmetric with respect to the plasma potential and shifting the floating potential towards the plasma potential. Only the simplest case of an EEP floating exactly on the plasma potential is discussed here in which case no sheath is present around the probe. An ESP, principally operable only in strong magnetic fields, screens off most of the plasma electron current from the probe collector, taking advantage of the fact that the gyro radius of electrons is usually much smaller than that of the ions. Also in this case we obtain a symmetric current-voltage characteristic and a shift of the probe's floating potential towards the plasma potential. We have developed strong and robust EEPs and two types of ESPs, called BUnker Probes (BUP), for the use in the Scrape-Off Layer (SOL) of Medium-Size Tokamaks (MST), and other types of strongly magnetized hot plasmas. These probes are presented in detail.
\end{abstract}

\section{Introduction}

Probes are almost as old as the realization that the socalled "fourth state of matter" is something very peculiar. It was Sir William Crookes who in a lecture for the British Association for the Advancement of Sciences at Sheffield, Friday, August 22, 1879, spoke the famous words: "So distinct are these phenomena from anything, which occurs in air or gas at the ordinary tension, that we are led to assume that we are here brought face to face with matter in a fourth state or condition, a condition as far removed from the state of gas as gas is from liquid" $[1,2]$. This is the story we usually hear. However, in his speech Crookes was actually referring to Michael Faraday who claimed as

\footnotetext{
${ }^{a}$ e-mail: Roman.Schrittwieser@uibk.ac.at
}

early as in 1819 that "matter may be classed into four states - solid, liquid, gaseous, and radiant" [2]! At his time, Faraday could not yet prove his claim, but he could show the probability of the existence of "radiant matter" "in a series of ingenious analogical arguments". Crookes adopted the term "radiant matter" in his speech. And it was also Crookes himself who used additional small electrodes in his experiments with gas discharges to find out what is going on in them. This was the hour of birth of plasma probes.

But of course, plasma probes (including emissive probes!) are inseparably connected to the name of the plasma pioneer Irving Langmuir who in his seminal work in 1923 $[3,4]$ for the first time points out on p. 4 of [3,4] "that very serious errors are made by attempting to measure potentials in ionised gases by using sounding electrodes" 
(i.e. cold probes). Further on, Langmuir describes two "simple methods by which the true space potentials can be measured". Langmuir continues: "In the first method a tungsten filament is used as sounding electrode, so arranged that it can be heated when desired" describing how the filament attains the same potential as the space around when the filament is sufficiently heated. This was the hour of birth of the emissive probe.

In the next paragraph on p. 4 of $[3,4]$ Langmuir describes the second method to determine the plasma potential by a cold probe (a "sounding probe") "by plotting the current on a semi-logarithmic paper against the potential". He continues "it is thus found that there is a definite kink in the curve at the point when the electrode potential is the same as that of the surrounding space". This method is the most familiar to us to determine the plasma potential (see also [5]).

Thus plasma probes are among the oldest plasma diagnostic tools, they are simple and inexpensive with good spatial and temporal resolution. Although they are usually accredited to Langmuir and often also denominated with his name, not only Crookes has used plasma probes before Langmuir, but e.g. also Stark et al. [6].

\subsection{Basic considerations}

The spatial profile and the temporal evolution of the plasma potential $\Phi_{\mathrm{pl}}$ are decisive not only for the overall stability of a plasma but also for the loss of plasma confinement, in particular in the case of a magnetically confined plasma such as in toroidal fusion experiments. Very important in this context is the electric field and its fluctuations in the edge region since edge plasma turbulence can give rise to the fluctuation-induced radial particle flux and to important effects such as the Reynolds stress (see e.g. [7]).

In this context we would like to remind us that the plasma potential solely depends on the densities of the positive and negative charge carriers but not on the specific form of the velocity distribution functions, in particular not on particle drifts or beams. The plasma potential is determined by Poisson's equation, where the charge density $\rho=e\left(n_{\mathrm{i}}-n_{\mathrm{e}}\right)$ is due to the presence of free positive and negative charge carriers (with the number densities $n_{\mathrm{i}, \mathrm{e}}$ of ions and electrons, respectively). Assuming a conventional isotropic plasma with electrons and only singlecharged positive ions we have:

$$
\Delta \Phi_{\mathrm{pl}}=-\frac{\rho}{\varepsilon_{0}}=-\frac{e}{\varepsilon_{0}}\left(n_{\mathrm{i}}-n_{\mathrm{e}}\right) .
$$

In view of its relevance for such phenomena it is of utmost importance to gain as much as possible information on the behaviour of $\Phi_{\mathrm{pl}}$. Unfortunately, however, there are very few diagnostics which are able to measure this parameter with sufficient spatial and temporal resolution. There are intricate methods such as electron beams and heavy ion beams but these are not easily applicable in all types of plasma and are also expensive. Therefore the practically only diagnostic tools which permit a comprehensive determination of $\Phi_{\mathrm{pl}}$ and, by use of probe arrays, of the electric field $\boldsymbol{E}=-\operatorname{grad} \Phi_{\mathrm{pl}}$, are plasma probes of various types and principles.

A reliable determination of the plasma potential and its spatial profile and temporal variations is, however, not an easy task. Usually Cold Langmuir Probes (CLP) would be quoted as diagnostic tools which could deliver this important parameter. The current-voltage characteristic $\left(I_{\mathrm{p}}-V_{\mathrm{p}}\right.$ characteristic) of a CLP, i.e., the total current $I_{\mathrm{p}}$ to the probe as function of the applied probe voltage $V_{\mathrm{p}}$, delivers in principle all information on the electron and ion density, $n_{\mathrm{e}, \mathrm{i}}$, the electron temperature, $T_{\mathrm{e}}$, the floating potential $V_{\mathrm{fl}}$ and the plasma potential $\Phi_{\mathrm{pl}}$ (see for instance [8-11]). But this works properly only in a Maxwellian plasma, i.e. a plasma with Maxwellian velocity distribution functions of electrons and ions. Then, as described by Langmuir [5], the inflection point or the "knee" of the $I_{\mathrm{p}}-V_{\mathrm{p}}$ characteristic, i.e. the transition from the electron retarding field region to the electron saturation current region is usually taken as more or less reliable measure of $\Phi_{\mathrm{pl}}$. Often it is, however, ignored that the entire characteristic of a cold probe shifts to the negative side and will therefore deliver erroneous results for the plasma potential whenever there is a strong deviation of the electron velocity distribution function from a Maxwellian one, for instance when there is a considerable electron drift, an electron beam or runaway electrons.

Furthermore we have to keep in mind that for the probe as such the reference potential is the plasma potential $\Phi_{\mathrm{pl}}$, while for recording the $I_{\mathrm{p}}-V_{\mathrm{p}}$ characteristic, $V_{\mathrm{p}}$ has to be referred to an external potential which in a plasma device usually is the grounded wall or one of the electrodes of the discharge that produces the plasma. This is an essential problem of plasma potential measurements with probes.

\subsection{Particle fluxes and basic facts on plasma probes}

The easiest measureable parameter of a plasma probe is its floating potential $V_{\mathrm{fl}}$, which in case of a CLP is of limited worth since $V_{\mathrm{fl}, \mathrm{cp}}$ will usually be more negative than the far more important plasma potential $\Phi_{\mathrm{pl}}{ }^{1}$. The reason for this is the usually strong imbalance between the magnitudes of the electron and ion current densities in a conventional plasma.

Even in a pure hydrogen plasma ("protium" plasma, to be exact [12]), the mass ratio of the ions to electrons, $m_{\mathrm{i}} / m_{\mathrm{e}}$, is 1836 . Assuming an isotropic Maxwellian plasma (i.e. with the velocity distribution functions of the ions and electrons being both Maxwellians in all directions), and a rather low plasma density so that it is collisionless or just weakly collisional, the mean velocities of ions (index " $i$ ") and electrons (index " $e$ ") are given by:

$$
\overline{\mathrm{v}}_{\mathrm{i}, \mathrm{e}}=\sqrt{\frac{8 k_{\mathrm{B}} T_{\mathrm{i}, \mathrm{e}}^{*}}{\pi m_{\mathrm{i}, \mathrm{e}}}} .
$$

1 Please note that the symbol $V_{\mathrm{f}}$ will be used for the floating potential of any type of probe, $V_{\mathrm{fl}, \mathrm{cp}}$ will signify the floating potential of a Cold Langmuir Probe (CLP), $V_{\text {fl,ep }}$ the floating potential of an Electron Emissive Probe (EEP), $V_{\mathrm{fl}, \mathrm{sp}}$ of an Electron Screening Probe (EPS). 
Here $T_{\mathrm{i}, \mathrm{e}}^{*}$ is the ion/electron temperature in $\mathrm{K}$. In the following we will use the convenient definition of the temperature in plasma physics: $k_{\mathrm{B}} T_{\mathrm{i}, \mathrm{e}}^{*}=T_{\mathrm{i}, \mathrm{e}}$ in $\mathrm{eV}$.

For equal temperatures of ions and electrons $T_{\mathrm{i}} \cong T_{\mathrm{e}}$, the ratio of their mean velocities $\overline{\mathrm{v}}_{\mathrm{i}} / \overline{\mathrm{v}}_{\mathrm{e}}$ thus comes down to $\sqrt{m_{\mathrm{e}} / m_{\mathrm{i}}}$, which for a protium plasma yields about $1 / 43$, or $1 / 61$ for a deuterium plasma.

Only in exotic plasmas, with the ions being much hotter than the electrons, or with a significant fraction of negative ions this ratio could become larger. To produce similar values of $\overline{\mathrm{v}}_{\mathrm{e}}$ and $\overline{\mathrm{v}}_{\mathrm{i}}$ in a conventional Maxwellian plasma the temperature of the ions would have to be larger by a factor of $m_{\mathrm{i}} / m_{\mathrm{e}}$ than the electron temperature. On the contrary, for instance in a glow discharge plasma the electron temperature is usually by up to two orders of magnitude higher than that of the ions, so that the ratio $\overline{\mathrm{v}}_{\mathrm{i}} / \overline{\mathrm{v}}_{\mathrm{e}}$ would even for a protium plasma be significantly smaller than $1 / 43$.

Since, strictly speaking, the current densities of electrons and ions, and thus also the currents as such, have opposite signs, we have always to compare their magnitudes. For the random electric current densities $\left|j_{\mathrm{i}, \mathrm{e}}\right|$ in a conventional isotropic Maxwellian plasma (which we assume to be also quasineutral: $n_{\mathrm{i}} \cong n_{\mathrm{e}} \cong n_{\mathrm{pl}}$ ) we therefore get:

$$
\left|j_{\mathrm{i}, \mathrm{e}}\right|=\frac{1}{4} e n_{\mathrm{i}, \mathrm{e}} \overline{\mathrm{v}}_{\mathrm{i}, \mathrm{e}}=\frac{1}{4} e n_{\mathrm{i}, \mathrm{e}} \sqrt{\frac{8 T_{\mathrm{i}, \mathrm{e}}}{\pi m_{\mathrm{i}, \mathrm{e}}}} .
$$

The factor $1 / 4$ stems from the integration of the particle flux onto a unit surface of any area inside the plasma from all directions of the half-space in front it. Note that so far we have assumed an isotropic plasma (without magnetic field).

With $A_{\text {pi }} / A_{\text {pe }}$ being the effective areas of the probe for collection of ions/electrons, in terms of currents we have:

$$
\left|I_{\mathrm{i}, \mathrm{e}}\right|=\frac{1}{4} A_{\mathrm{pi}, \mathrm{pe}} e n_{\mathrm{i}, \mathrm{e}} \overline{\mathrm{v}}_{\mathrm{i}, \mathrm{e}}=\frac{1}{4} A_{\mathrm{pi}, \mathrm{pe}} e n_{\mathrm{i}, \mathrm{e}} \sqrt{\frac{8 T_{\mathrm{i}, \mathrm{e}}}{\pi m_{\mathrm{i}, \mathrm{e}}}} .
$$

In case of a CLP we have, however, to take into account that the ion velocity in front of a negatively biased probe has to fulfil the Bohm criterion [13], i.e., it must be at least equal to the ion acoustic velocity, $\mathrm{v}_{\mathrm{a}}=\sqrt{\left(T_{\mathrm{e}}+\gamma T_{\mathrm{i}}\right) / m_{\mathrm{i}}}$ (with $\gamma$ being the adiabatic coefficient for ions which, as usual, we assume to be $\gamma=3$ ). This requires the formation of a presheath in front of the actual probe sheath to accelerate the ions to $\mathrm{v}_{\mathrm{a}}[13-15]$. This in turn leads to a slight reduction of the ion density in front of the sheath edge so that the eventual value of the ion saturation current $I_{\text {is }}$ to a negatively biased probe will be:

$$
I_{\text {is }}=+0.61 A_{\mathrm{pi}} e n_{\mathrm{i}} \sqrt{\frac{T_{\mathrm{e}}+\gamma T}{m_{\mathrm{i}}}} .
$$

For the electron saturation current, on the other hand, we can take equation (4):

$$
I_{\mathrm{es}}=-\frac{1}{4} A_{\mathrm{pe}} e n_{\mathrm{e}} \overline{\mathrm{v}}_{\mathrm{e}}=-\frac{1}{4} A_{\mathrm{pe}} e n_{\mathrm{e}} \sqrt{\frac{8 T_{\mathrm{e}}}{\pi m_{\mathrm{e}}}} .
$$

Since we will mainly concentrate on the use of probes in strongly magnetized, and thus non-isotropic plasmas, in particular the electrons will propagate almost on onedimensional trajectories. In this case the mean electron velocity has to be modified and equation (6) will become:

$$
I_{\mathrm{es}}=-A_{\mathrm{pe}} e n_{\mathrm{e}} \overline{\mathrm{v}}_{\mathrm{e}}=-A_{\mathrm{pe}} e n_{\mathrm{e}} \sqrt{\frac{2 T_{\mathrm{e}}}{\pi m_{\mathrm{e}}}} .
$$

As we will see further down, in strong magnetic fields the effective collecting areas $A_{\mathrm{pi}} / A_{\mathrm{pe}}$ of a probe can differ for ions and electrons. The ion/electron currents given in equations (5) and (7) are equal to the saturated probe currents when a CLP is sufficiently biased negatively/ positively with respect to $\Phi_{\mathrm{pl}}$ to completely repel the random electron/ion current in the plasma. Therefore we use the denominations $I_{\text {is,es }}$ for these currents.

It goes without saying that in any non-Maxwellian and/ or non-isotropic plasma, which is not quasineutral or where especially the electrons have a drift due to a current flowing through the plasma, or where there is an electron beam due to some external electric field, the mean electron velocity could differ strongly from the Maxwellian value. Such effects can for instance also be caused by double layers forming in a plasma $[16,17]$. We point out that in such cases a sufficiently strong Electron-Emissive Probe (EEP) will still work properly, be it in a magnetized or nonmagnetized plasma, whereas an Electron-Screening Probe (ESP) needs a magnetized plasma and works properly in principle only in Maxwellian plasmas.

As a consequence of equation (1), equation (4) shows that the magnitude of the random electron current in such a plasma is much higher than that of the ions. Obviously also the saturation currents to a CLP (Eqs. (5) and (7)) are strongly different. This has three unpleasant consequences:

(i) For strong negative/positive biases on a CLP the positive/negative currents drawn by the probe $I_{\text {is,es }}$ will be strongly different in magnitude.

(ii) The current-voltage characteristic $\left(I_{\mathrm{p}}-V_{\mathrm{p}}\right.$ characteristic) of the probe will be asymmetric around $\Phi_{\mathrm{pl}}$.

(iii) The probe's floating potential $V_{\mathrm{fl}, \mathrm{cp}}$ will be more negative than $\Phi_{\mathrm{pl}}$ by a factor proportional to the electron temperature $T_{\mathrm{e}}$ (see Eq. (8) and the black line in Fig. 1).

Considering the plasma potential $\Phi_{\mathrm{pl}}$ as the most important parameter, we have made efforts to develop probes with which we could measure it directly. This means our efforts were concentrated on the development of probes which float on, or at least approximately near $\Phi_{\mathrm{pl}}$, since measuring a floating potential is not only easy but also guarantees high spatial and temporal resolution, the latter being limited practically only by the scanning rate of the data acquisition system $(>\mathrm{MHz})$. For simplicity we have named such probes Plasma Potential Probes (PPP).

Sure, in a Maxwellian plasma without any electron drift or beam we could derive $\Phi_{\mathrm{pl}}$ also from the $I_{\mathrm{p}}-V_{\mathrm{p}}$ characteristic of a CLP $[5,8]$, but this means that the $I_{\mathrm{p}}-V_{\mathrm{p}}$ characteristic has to be scanned as fast as possible, for which there are also physical limits, mainly due to capacitive 


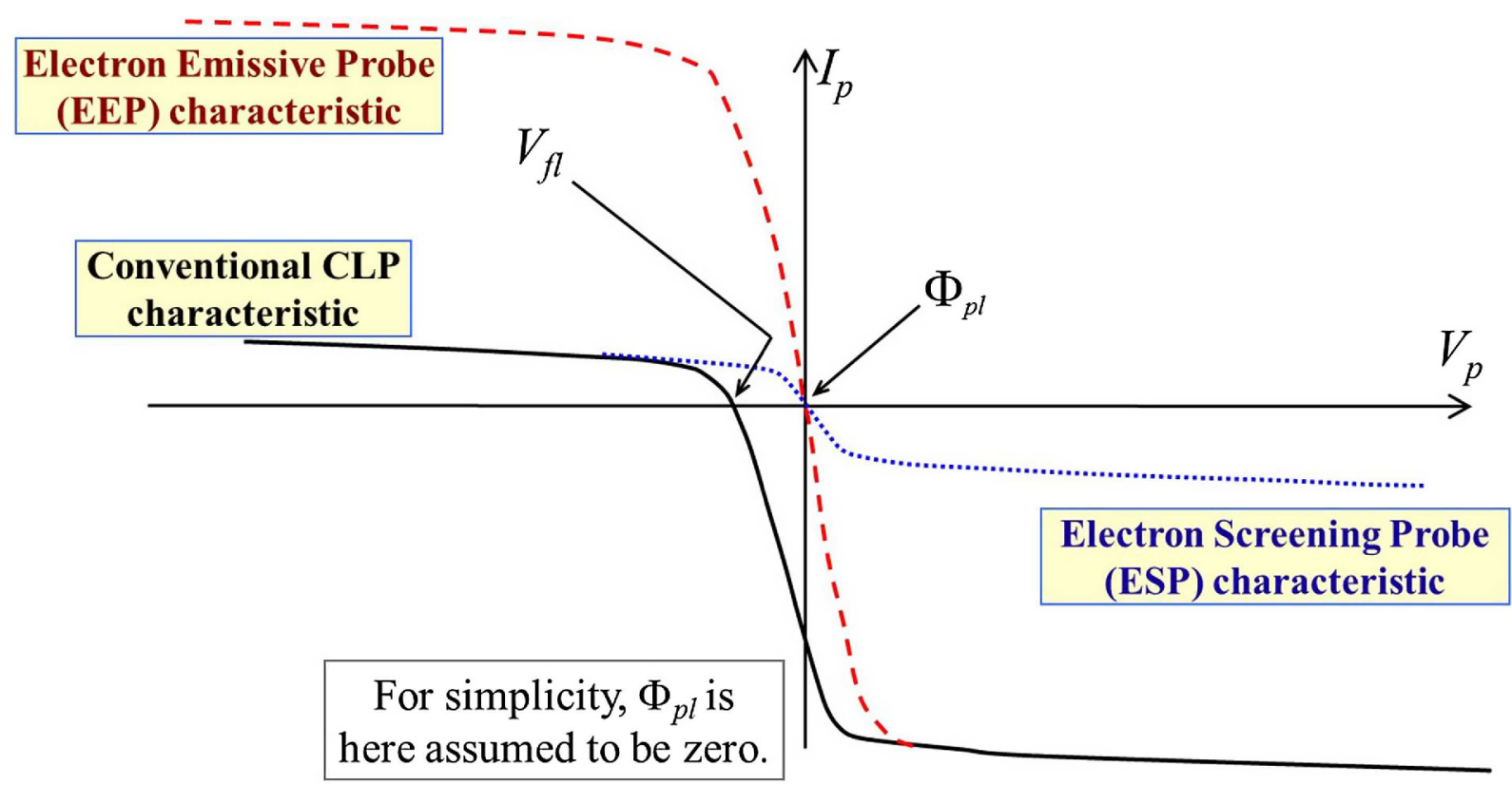

Fig. 1. Schematics of current-voltage characteristics of three different types of probes in a conventional Maxwellian plasma: the black line shows the $I_{\mathrm{p}}-V_{\mathrm{p}}$ characteristic of a normal Cold Langmuir Probe (CLP), the red dashed line that of an Electron Emissive Probe (EEP) (see Sect. 2), the blue dotted line that of an Electron Screening Probe (ESP) (see Sect. 3). For simplicity the plasma potential $\Phi_{\mathrm{pl}}$ is here assumed to be zero.

effects of the probe sheath. And even with a high scanning rate and automatizing the evaluation of an $I_{\mathrm{p}}-V_{\mathrm{p}}$ characteristic as well as possible, the best temporal resolution to determine any temporal evolution of $\Phi_{\mathrm{pl}}$ would be in range of tens of $\mathrm{kHz}[18]$.

Another important advantage of a floating probe is that there is no net current through it as positive and negative currents cancel each other. And since a PPP is supposed to float more or less exactly on $\Phi_{\mathrm{pl}}$, there should in principle be no sheath around it, wherefore it will cause the least perturbation to the plasma [19], and we do not need to take into account space charge limiting effects of the probe current or orbital motion effects. In case of an EEP there is a caveat here which will be discussed below in Section 2.

Moreover, possible damages of the probe by hot and hazardous plasmas will be the least for a probe floating on the plasma potential. Any probe bias apart from $V_{\mathrm{fl}} \cong \Phi_{\mathrm{pl}}$, which is inevitable when recording the probe's $I_{\mathrm{p}}-V_{\mathrm{p}}$ characteristic, will lead to a net current from the plasma to the probe. In particular in hot plasmas the sweeping range of the probe voltage has to be up to $\pm 100 \mathrm{~V}$ or even more. For negative biases this can lead to secondary electron emission from the probe into the plasma or even to sputtering of the probe surface due to energetic ions. In case of positively biasing the probe might be heated up to emission or even above the melting point due to a strong electron current $I_{\mathrm{es}}$ or might even start evaporating. Both effects can not only lead to damages of the probe or its untimely death, but the sputtered-off or evaporated probe material can also deposit on other parts of the vacuum system, there possibly giving rise to unwanted short circuits or leakage currents.
So to attain $V_{\mathrm{ff}} \cong \Phi_{\mathrm{pl}}$ our efforts must be directed to compensate the strong difference between the magnitudes of the positive/negative probe currents $I_{\text {is,es }}$. This is tantamount to making the probe's current-voltage characteristic $\left(I_{\mathrm{p}}-V_{\mathrm{p}}\right.$ characteristic) symmetric with respect to $\Phi_{\mathrm{pl}}$.

Basically there are two methods to attain this goal:

(i) The plasma electron current $\left|I_{\text {es }}\right|$ towards the probe can be compensated by an approximately equal electron emission current $\left|I_{\mathrm{em}}\right|$ from the probe into the plasma.

(ii) The excess of random plasma electron current $\left|I_{\mathrm{es}}\right|$, as compared to the ion current $\left|I_{\text {is }}\right|$, must be screened off the probe until it roughly equals $\left|I_{\text {is }}\right|$.

Method (i): This is realised in EEPs by heating the probe until sufficient electron emission occurs due to the Richardson-Dushman effect [20]. We emphasize here that an EEP would still work properly, i.e., floating on $\Phi_{\mathrm{pl}}$, if the total plasma electron current is higher than the random current (Eq. (4)) due to additional effects, provided that the emission current is high enough to compensate also the additional electron current. Mainly we refer to electron drifts or additional electron beams and it means that an EEP is therefore the only diagnostic tool for measuring spatial profiles of $\Phi_{\mathrm{pl}}$ in plasmas e.g. with DLs $[16,17]$ or even more complicated potential formations (see e.g. $[21,22])$. Furthermore EEPs do work also in non-magnetized plasmas.

As we have seen also the EEP has been first described by Langmuir [3-5]. He found that the floating potential of a conventional wire loop EEP jumped from a negative value of the voltage for an unheated wire to a more positive value when the wire was strongly heated. A more detailed 
description and treatment of the EEP and our contribution to their development by Schneider et al. [23,24] is presented in Section 2.

Method (ii): This can in principle only be attained in strong magnetic fields in Maxwellian plasmas with ESPs such as Ball-Pen Probes (BPP) [25-27] or the new BUnker Probe (BUP) by Costea et al. [28]. ESPs are all based on the principle of the probe developed by Katsumata and Okazaki $[29,30]$. The cylindrical collector of this probe was inserted in a metallic screening tube, isolated from it. When this probe was inserted perpendicular to the strong magnetic field $\boldsymbol{B}$ of a Q-machine $([31,32])$ and the collector was retracted inside the tube, the electrons could be screened-off geometrically from the collector due to their much smaller gyro radii in $\boldsymbol{B}$, whereas ions could still reach the collector on their much wider helical trajectories. By varying how far the collector was retracted inside the screening tube, Katsumata could successfully scan the energy distribution of the ions perpendicular to $\boldsymbol{B}$, almost - but not completely - without electrons.

Adámek et al. [25-27] took use of this principle for another purpose. Taking advantage of the finding that even with a deeply retracted collector still a small electron current could find its way to the collector due to $\boldsymbol{E} \times \boldsymbol{B}$ drift effects, they developed the Ball-Pen Probe (BPP). And for almost equal magnitudes of the ion and the electron current a symmetric $I_{\mathrm{p}}-V_{\mathrm{p}}$ characteristic was obtained with the floating potential indeed very precisely on the plasma potential, thus $V_{\mathrm{fl}, \mathrm{sp}} \cong \Phi_{\mathrm{pl}}$. A more detailed description of the BBP and the ESP derived from it (BUP) is presented in Section 3.

Figure 1 shows the modes of action of the two methods schematically.

The black line in Figure 1 shows an $I_{\mathrm{p}}-V_{\mathrm{p}}$ characteristic of a CLP in a conventional Maxwellian plasma schematically, here shown in the physical current direction. Whereas for the plasma the reference potential for the $I_{\mathrm{p}}-V_{\mathrm{p}}$ characteristic is $\Phi_{\mathrm{pl}}$, in reality (as we have seen) an $I_{\mathrm{p}}-V_{\mathrm{p}}$ characteristic can only be recorded with respect to an external reference electrode. The plasma potential can be derived from the inflection point of the characteristic but - as mentioned above - only by evaluating more or less the entire the $I_{\mathrm{p}}-V_{\mathrm{p}}$ characteristic each time [18].

For a very negative bias of the probe with respect to $\Phi_{\mathrm{pl}}$, only ions can reach the probe whereas electrons are repelled. On the positive side, when all ions are repelled, only electrons can flow towards the probe giving rise to current with a much higher magnitude than that of the ions; therefore, as mentioned above (Eqs. (5)-(7), respectively), $\left|I_{\text {is }}\right|<<\left|I_{\mathrm{es}}\right|$, and $V_{\mathrm{fl}}$ is shifted towards the negative side, away from the plasma potential.

The red dashed line in Figure 1 shows a schematic example of an EEP characteristic with the electron emission current $I_{\text {em }}$ from the probe into the plasma superposing on the current of ions from the plasma towards the probe $I_{\text {is }}$. Usually the emission current $I_{\mathrm{em}}$ is then much higher than the ion current $I_{\text {is }}$ to the probe, the latter becoming almost negligible. We see the shift of the floating potential of the EEP, $V_{\mathrm{fl}, \mathrm{ep}}$, to the positive side, becoming equal to $\Phi_{\mathrm{pl}}$.

Ideally the plasma electron current on the right-hand side of the $I_{\mathrm{p}}-V_{\mathrm{p}}$ characteristic of an EEP is not altered by the electron emission of the probe since the emitted electrons cannot leave the probe surface when the probe is more positive than the plasma. In reality under certain circumstances, mainly depending on the geometry of the probe, the electron current is yet sometimes perturbed by the emission effect $[33,34]$, but this has not necessarily any effect on the floating potential $V_{\text {fl,ep }}$.

The blue dotted line shows a schematic example of an ESP characteristic where the magnitude of the plasma electron current towards the probe, $\left|I_{\mathrm{es}}\right|$, is reduced by the screening tube until becoming approximately equal to the magnitude of the ion current, $\left|I_{\text {is }}\right|$. Analogously to the case of the EEP, here the ion current on the left-hand side of the $I_{\mathrm{p}}-V_{\mathrm{p}}$ characteristic should ideally not be altered by the screening of the electron current. But in reality also the ion current is slightly diminished by the screening tube [25-27].

\subsection{Idealized theory of the floating CLP}

In order to understand the working principles of EEPs and ESPs, we have briefly to return to the principle of a CLP: For floating conditions, i.e., probe current $I_{\mathrm{p}}=0$, we obtain the following simplified relation between the cold floating potential $V_{\mathrm{fl}, \mathrm{cp}}$ and the plasma potential $\Phi_{\mathrm{pl}}$ $[35,36]$ :

$$
V_{\mathrm{fl}, \mathrm{cp}}=\Phi_{\mathrm{pl}}-\ln \left(\frac{\left|I_{\mathrm{es}}\right|}{\left|I_{\mathrm{is}}\right|}\right) \frac{T_{\mathrm{e}}}{e}=\Phi_{\mathrm{pl}}-\alpha_{\mathrm{cp}} \frac{T_{\mathrm{e}}}{e} .
$$

For the sake of completeness we have to mention that another frequently applied method to determine $\Phi_{\mathrm{pl}}$, especially often applied in toroidal fusion experiment, is to measure the floating potential of a CLP, $V_{\text {fl,cp }}$, and to transform equation (8):

$$
\Phi_{\mathrm{pl}}=V_{\mathrm{fl}, \mathrm{cp}}+\ln \left(\frac{\left|I_{\mathrm{es}}\right|}{\left|I_{\mathrm{is}}\right|}\right) \frac{T_{\mathrm{e}}}{e} .
$$

So if $T_{\mathrm{e}}$ can be determined simultaneously, the plasma potential can in principle be calculated. However, not only reliable measurements of $T_{\mathrm{e}}$ as such are difficult, with temporal or spatial variations of $T_{\mathrm{e}}$ the calculation of $\Phi_{\mathrm{pl}}$ $\left(V_{\mathrm{fl}, \mathrm{cp}}, T_{\mathrm{e}}\right)$ can become very complicated or even impossible. If more than one CLP is used for instance to determine the electric field component in the direction of the connection length of the two probes, often it is simply assumed that $T_{\mathrm{e}}$, including its fluctuations, is the same on the positions of the two probes, and for $T_{\mathrm{e}}$ an educated guess is made. It goes without saying that frequently this is a rather daring assumption.

Also from equation (8) we see that $V_{\mathrm{fl}, \mathrm{cp}}$ is always more negative than $\Phi_{\mathrm{pl}}$ by the factor $\alpha_{\mathrm{cp}} T_{\mathrm{e}} / e=\ln \left(\left|I_{\mathrm{es}}\right| /\left|I_{\mathrm{is}}\right|\right)$ $T_{\mathrm{e}} / e$ which, according to Eqs. (5) and (7), depends on the ion mass $m_{\mathrm{i}}$, the temperature $T_{\mathrm{e}}$, but also on the effective collecting area of the probe $A_{\mathrm{pe}}$ or $A_{\mathrm{pi}}$. In a strong magnetic field, as e.g. in a tokamak with $\boldsymbol{B}$ around $1 \mathrm{~T}$, and in the Scrape-Off Layer (SOL) with $T_{\mathrm{e}} \cong 50 \mathrm{eV}$ (see Sect. 3.1), the electron gyro radius $r_{\mathrm{e}} \cong 16.8 \mu \mathrm{m}$, while for deuterium and also $T_{\mathrm{i}} \cong 50 \mathrm{eV}, r_{\mathrm{i}} \cong 1.02 \mathrm{~mm}$. These 
values have to be set in relation to the dimensions of a typical cylindrical probe pin (radius $r_{\mathrm{p}} \cong 0.5 \mathrm{~mm}$, length $l_{\mathrm{p}} \cong 3 \mathrm{~mm}$ ) [7]. Following [35], we therefore assume that for the electrons the effective probe collecting area corresponds only to twice the cross section of the probe pin $A_{\mathrm{pe}}=2 \cdot 2 r_{\mathrm{p}} l_{\mathrm{p}}$, whereas the ions are less magnetized in the surroundings of the probe, "seeing" the entire surface of the cylinder, including the circular top: $A_{\mathrm{pi}}=$ $\pi\left(2 r_{\mathrm{p}} l_{\mathrm{p}}+r_{p}^{2}\right)$. Inserting equations (5) and (7) and $n_{\mathrm{e}} \cong$ $n_{\mathrm{i}} \cong n_{\mathrm{pl}}$, in this case $\left|I_{\mathrm{es}}\right| /\left|I_{\mathrm{is}}\right|$ will become:

$$
\begin{aligned}
\frac{\left|I_{\mathrm{es}}\right|}{\left|I_{\mathrm{is}}\right|} & =\frac{A_{\mathrm{pe}}}{0.61 A_{\mathrm{pi}}} \sqrt{\frac{2 m_{\mathrm{i}} T_{\mathrm{e}}}{\pi m_{\mathrm{e}}\left(T_{\mathrm{e}}+\gamma T_{\mathrm{i}}\right)}} \\
& \cong 1.66 \frac{l_{\mathrm{p}}}{\left(2 l_{\mathrm{p}}+r_{\mathrm{p}}\right)} \sqrt{\frac{m_{\mathrm{i}} T_{\mathrm{e}}}{m_{\mathrm{e}}\left(T_{\mathrm{e}}+\gamma T_{\mathrm{i}}\right)}} .
\end{aligned}
$$

For our values for $r_{\mathrm{p}}, l_{\mathrm{p}}$, and $m_{\mathrm{i}}$ (deuterium) we obtain, $\left|I_{\mathrm{es}}\right| /\left|I_{\mathrm{is}}\right| \cong 23.2$, and for $\alpha_{\mathrm{cp}}$ we get $\alpha_{\mathrm{cp}} \cong 3.15$. This value is in good agreement with previous considerations and measurements (see e.g. [26,35]). We note that under our exemplary conditions the electron/ion saturation currents to a probe pin are: $I_{\mathrm{es}} \cong 22.6 \mathrm{~A}$ and $I_{\text {is }} \cong 0.975 \mathrm{~A}$, respectively.

\section{Electron Emissive Probes (EEP)}

\subsection{Basics of electron emissive probes (EEP)}

Sellen et al. [37] and Kemp and Sellen [38] were among the first to use emissive wire probes for direct measurements of the plasma potential by using the floating potential method under strong electron emission. Another important, however, indirect method was later described by Smith et al. [39] who argued that the inflection point of an emissive probe characteristic, at moderate emission current, yields a more precise measure for the plasma potential. Later on, eminent contributions to the plasma diagnosis with emissive probes were made especially by Hershkowitz and his group [40-50]. Other papers were devoted mainly to the experimental and theoretical principles of emissive probes [19,21,33-36,51-77]. Also dust grains have turned out to become emissive when heated in dusty plasmas [78].

Until the end of the 1990's emissive probes were used almost exclusively in low-temperature plasma devices, and even this rather seldom. As for instance Hershkowitz comments [11] on Chen [8]: "they [EEPs] have not found widespread use because of problems associated with strong electron emission and because of generally negative comments about them in previous review articles". This was probably also the reason that, as far as we know, the first successful applications of emissive probes in small tokamaks (CASTOR and ISTTOK) were reported not before the year $2000[19,26,35,51,52,61,72]$ (see also [23,24]). One use is reported in Alcator C-Mod [79].

While a detailed review on EEPs is not within the scope of the present paper, for the most comprehensive presentation of EEPs we refer especially to the excellent review by Sheehan and Hershkowitz [46]. Also the recent paper by Sheehan et al. [50] is very recommendable to give information on the practical use of EEPs.

As it has recently become more and more obvious that in future large tokamaks such as ITER [80] the plasma heat flux onto Plasma Facing Components (PFC) can be as high $60 \mathrm{MW} \mathrm{m}^{-2}$, a strong heating of the divertor plates up to white glow and consequent electron emission cannot be completely ruled out. This has renewed the interest in the interaction of plasmas with emissive walls [81-83] since, if the entire divertor becomes emissive, this will obviously have a drastic effect on the entire tokamak plasma.

Since we are mainly interested in a handy and straightforward use of EEPs for measuring the plasma potential in the simplest and most convenient way with high temporal resolution, we settle here for the basic property of such a probe assuming that it really floats on the plasma potential. We therefore also ignore the possible formation of space charge sheaths around the probe. An electrode that has exactly the same potential as the surrounding plasma has per definitionem no sheath in front of it, implying that the ion and electron fluxes from the plasma are not deflected or in any way hampered by an electric field in front of the EEP. We have therefore also not to worry about space charge limiting effects or orbital motions of the particles around the probe. Likewise also the emitted electron flux is not affected in any way.

An electron emissive probe is usually realized by a small half-loop of a tungsten or thoriated tungsten wire or a wire of another refractory metal ( $\mathrm{Ta}, \mathrm{Mo}$ or $\mathrm{Re}$ ) with a diameter of $0.05-0.2 \mathrm{~mm}$. The two ends of this half-loop are pulled through the two bores of a double-bore ceramic tube and are at the other end connected by feed-throughs to an external power supply. Thus the loop can be heated to the necessary temperature for electron emission. In order to heat only the protruding refractory wire loop but not the parts inside the ceramic tube, we have devised a simple method to increase the conductivity of the wires inside the bores: the tungsten wires are spliced with a number of very thin copper threads which on the other end of the ceramic tube also provide the connection to the power supply or battery. For more details see our previous works $[19,35,57,61,72]$. Figure 2 shows a schematic presentation of an emissive wire probe with the particle fluxes and currents, respectively, on it.

For an emissive probe, equation (8) modifies as follows $[19,36]$ :

$$
V_{\mathrm{fl}, \mathrm{ep}}=\Phi_{\mathrm{pl}}-\ln \left(\frac{\left|I_{\mathrm{es}}\right|}{\left|I_{\mathrm{is}}+I_{\mathrm{ep}}\right|}\right) \frac{T_{\mathrm{e}}}{e}=\Phi_{\mathrm{pl}}-\alpha_{\mathrm{ep}} \frac{T_{\mathrm{e}}}{e} .
$$

Here $V_{\mathrm{fl} \text {,ep }}$ is the actual floating potential of the EEP which changes with the emission current $I_{\mathrm{ep}}$. $V_{\mathrm{fl}, \mathrm{ep}}$ is obviously equal to $V_{\mathrm{fl}, \mathrm{cp}}$ for $I_{\mathrm{ep}}=0$ (i.e. for a CLP) and will approach $\Phi_{\mathrm{pl}}$ for increasing probe heating, i.e. increasing emission current $I_{\mathrm{ep}}$. The factor $\alpha_{\mathrm{ep}}$ (which in Eq. (8) was called $\alpha_{\mathrm{cp}}$ ) now becomes:

$$
\alpha_{\mathrm{ep}}=\ln \left(\frac{\left|I_{\mathrm{es}}\right|}{\left|I_{\mathrm{is}}+I_{\mathrm{ep}}\right|}\right) \equiv \frac{e\left(\Phi_{\mathrm{pl}}-V_{\mathrm{fl}, \mathrm{ep}}\right)}{T_{\mathrm{e}}} .
$$




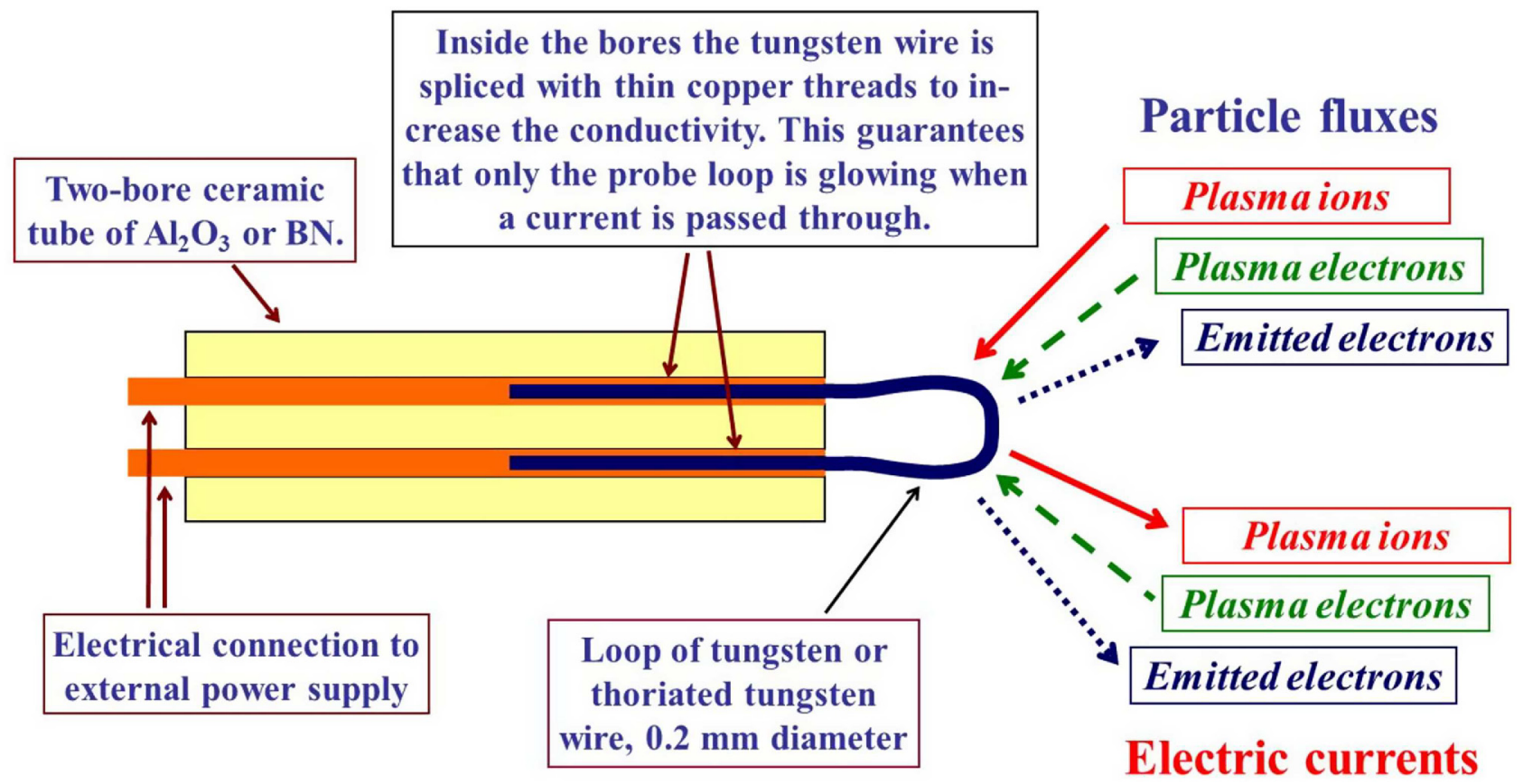

Fig. 2. Schematic of a conventional EEP consisting of a loop of refractory wire. The connections with the copper threads inside the ceramic double-bore tube are made according to [57]. On the right-hand side up the particle fluxes to and from the probe are shown schematically, below the corresponding electric currents are indicated.

As we can see, $\alpha_{\text {ep }}$ is also proportional to the difference between the plasma potential $\Phi_{\mathrm{pl}}$ and the floating potential of the emissive probe $V_{\mathrm{fl}, \mathrm{ep}}$.

For the emission current $I_{\mathrm{ep}}$ we have to insert Richardson-Dushman's emission law [20]:

$$
I_{\mathrm{ep}}=A_{\mathrm{ep}} A^{*}\left(\frac{T_{w}}{k_{\mathrm{B}}}\right)^{2} \exp \left(-\frac{W_{w}}{T_{w}}\right)
$$

with $A_{\text {ep }}$ being the effective emitting area of the probe, $A^{*}$ the Richardson constant, $k_{\mathrm{B}}$ the Boltzmann constant, $T_{w}$ the temperature of the wire and $W_{w}$ the work function of the wire material (see Table 1 in [23]).

The theoretical value of $A^{*}$ is given by:

$$
A^{*}=4 \frac{\pi m_{\mathrm{e}} k_{\mathrm{B}}^{2} e}{h^{3}}=12.1 \times 10^{5} \mathrm{~A} \mathrm{~m}^{-2} \mathrm{~K}^{-2},
$$

with $h=6.626 \times 10^{-34} \mathrm{~J}$ s being Planck's constant. But for various materials $A^{*}$ can deviate very strongly from this value (see Tab. 1 in [23]).

From equation (11) we see that for increasing emission current $I_{\mathrm{ep}}$, the second term decreases and vanishes for

$$
\left|I_{\mathrm{ep}}\right|=\left|I_{\mathrm{es}}\right|-\left|I_{\mathrm{is}}\right|,
$$

while $\alpha_{\mathrm{ep}}$ in equation (12) becomes zero. Thus when the emission current just compensates the electron saturation current (minus the - generally negligible - ion saturation current), the floating potential of such a probe equals the plasma potential:

$$
V_{\mathrm{fl}, \mathrm{ep}}=\Phi_{\mathrm{pl}} .
$$

This is what we want!
Of course this derivation is simplified insofar as we have neglected the possible formation of space charges in front of an EEP $[76,77,83,84]$. Especially if there is a strong mismatch between the temperatures $T_{\mathrm{em}}$ of the emitted electrons and of the plasma electrons $T_{\mathrm{e}}$, several experiments $[33,34]$, theoretical $[59,60,65]$ and numerical investigations [84] have indicated that the floating potential even of a very strongly emitting electrode in a plasma could always remain below $\Phi_{\mathrm{pl}}$. Inevitably the emitted electrons have a very low temperature which approximately corresponds to that of the emitting material, thus $T_{\mathrm{em}} \cong T_{w} \cong 0.2 \mathrm{eV}$, while practically all conceivable plasmas have higher temperatures, save exotic ones like Q-machine plasmas whose electrons stem also from thermionic emission [31,32]. But discharge plasmas can per se hardly have any lower electron temperature than at least one $\mathrm{eV}$, thus about five times higher than $T_{\mathrm{em}}$. We refer here in particular to the seminal work by Marek et al. [34] who compared three plasmas with electron temperatures $T_{\mathrm{e}}$ between $0.3 \mathrm{eV}$ and almost $5 \mathrm{eV}$, coming to the conclusion that only for lower values of $T_{\mathrm{e}}<1 \mathrm{eV}$ the floating potential of a conventional wire EEP, $V_{\mathrm{fl}, \mathrm{ep}}$, is close to $\Phi_{\mathrm{pl}}$, whereas for higher values of $T_{\mathrm{e}}$, above a few eV, $V_{\mathrm{fl}, \mathrm{ep}}$ tends to stay below $\Phi_{\mathrm{pl}}$.

In their theoretical papers $[59,60,65]$ Takamura et al. also come to the conclusion that $V_{\mathrm{fl}, \mathrm{ep}}$ remains always below $\Phi_{\mathrm{pl}}$ by a value around $0.9 T_{\mathrm{e}}$.

Gyergyek and Kovačič carried out many complex PIC (Particle-In Cell) investigations of a plasma with one electron emitting surface [84]. They found that there can be complex space charge structures in front of the emitting surface with several maxima and minima, thus even more complicated than DLs $[16,17]$. Also other authors came to 
this conclusion $[76,77,83]$. On the other hand, Campanell and Umansky [82] showed that a strongly emitting surface is unable to float below the plasma potential.

Also experimental data obtained with a laser-heated EEP showed that sometimes even in a helicon discharge plasma with $T_{\mathrm{e}} \cong 6 \mathrm{eV}, V_{\mathrm{fl}, \text { ep }}$ can reach values above $\Phi_{\mathrm{pl}}$ where the latter one was determined in the conventional way from the first derivative of the $I_{\mathrm{p}}-V_{\mathrm{p}}$ characteristic of a CLP (the unheated EEP), specifically $\Phi_{\mathrm{pl}}=10.6 \mathrm{~V}$, $V_{\text {fl,ep }}=11.2 \mathrm{~V}$ (see Fig. 4 in [74]).

Another evidence that EEPs do not necessarily float below $\Phi_{\mathrm{pl}}$ can be drawn from experiments with selfemitting probes and Ball-Pen Probes (BPP) [25,26] even in the plasmas of the COMPASS tokamak and ASDEX Upgrade [85], i.e., in Medium-Size Tokamaks (MST) for electron temperatures in the range of a $10 \mathrm{eV}$ and more. A graphite CLP pin on a probe head with several BPPs and CLPs was heated so strongly by the heat and particle flux in the SOL of COMPASS and ASDEX Upgrade that a few tens of ms after insertion of the probe into the SOL the pin became strongly electron emissive. This was observed on its floating potential $V_{\mathrm{fl} \text {,ep }}$ which suddenly jumped to much more positive values, and comparisons with the floating potential of a nearby BPP, $V_{\mathrm{fl}, \mathrm{sp}}$, showed that the values were almost equal, i.e. $V_{\mathrm{fl}, \mathrm{ep}} \cong V_{\mathrm{fl}, \mathrm{sp}}$. Since the floating potential of a BPP has been proven to be a reliable measure of the plasma potential [26], we conclude from these results, that the self-emitting graphite probe was also floating around $\Phi_{\mathrm{pl}}$.

For a more detailed discussion of the BPP and other Electron Screening Probes (ESP) see further below.

\subsection{Emission current of EEPs}

The most crucial point of an EEP is the emission current $\left|I_{\text {ep }}\right|$, which has, as we have seen (Eq. (15)) at least to be equal to the difference between the magnitudes of the saturation currents of the electrons and that of the ions (Eqs. (5) and (7)). In the following, for more generality, we resort to the current densities, i.e., from [23] we take the following condition, which the emitted current density has to fulfill to comply with equation (15):

$$
\left|j_{\mathrm{em}}\right|=\left|j_{\mathrm{es}}\right|-\left|j_{\mathrm{is}}\right|=e n_{\mathrm{pl}}\left(\sqrt{\frac{2 T_{\mathrm{e}}}{\pi m_{\mathrm{e}}}}-0.61 \sqrt{\frac{\left(T_{\mathrm{e}}+\gamma T_{\mathrm{i}}\right)}{m_{\mathrm{i}}}}\right) .
$$

For our exemplary deuterium SOL plasma with $T_{\mathrm{e}}=$ $50 \mathrm{eV}, B \cong 1 \mathrm{~T}$, and now a typical SOL density of $n_{\mathrm{pl}} \cong$ $10^{19} \mathrm{~m}^{-3}$ we obtain $\left|j_{\text {es }}\right|-\left|j_{\text {is }}\right| \cong 3.69 \times 10^{6} \mathrm{~A} \mathrm{~m}^{-2}$. For extreme electron temperatures of $T_{\mathrm{e}} \cong 100 \mathrm{eV}$ near the Last Closed Flux Surface (LCFS) (infinitesimally close to the separatrix) of a MST, $\left|j_{\text {es }}\right|-\left|j_{\text {is }}\right|$ can become as high as $5.28 \times 10^{6} \mathrm{~A} \mathrm{~m}^{-2}$.

These values have to be set in relation to the highest possible emission current densities from various materials. Schneider et al. [23,24] have shown that the best suited electron-emitting material, combining a relatively low work function of $W_{w}=3.35 \mathrm{eV}$ and a high heat resistance up to $3420 \mathrm{~K}$, is titanium carbide (TiC). The above current density of $\left|j_{\text {es }}\right|-\left|j_{\text {is }}\right|=5.28 \times 10^{6} \mathrm{~A} \mathrm{~m}^{-2}$ for $n_{\mathrm{pl}} \cong$ $10^{19} \mathrm{~m}^{-3}$ and $T_{\mathrm{e}}=100 \mathrm{eV}$ is matched by the emission current density $\left|j_{\mathrm{ep}}\right|$ of $\mathrm{TiC}$ for a temperature of $3000 \mathrm{~K}$, thus safe $420 \mathrm{~K}$ below its sublimation point.

\subsection{Alternative heating methods for an EEP}

Although the direct electric heating method of a conventional EEP, consisting of a high melting metallic wire loop, is the simplest and most straightforward, it has several drawbacks:

- The most frequently used materials are refractory metals such as W, Ta, Mo or Re, which all have high work functions $W_{w}$ and therefore low electron emission (Eq. (13) above, and Tab. 1 in [24]).

- This means that wires of these metals need to be heated very strongly for sufficient emission, often close to their melting points. This increases the evaporation of the probe wire and reduces their lifetime. For application in the SOL of MSTs they are practically out of question.

- The form of a conventional EEP is more or less limited to a loop of wire. This makes it necessarily larger than a CLP, which can be made of a single probe pin carried by a single ceramic tube.

- A current-carrying wire loop as shown in Figure 2 can be twisted by the Lorentz force when the EEP is used in magnetized plasmas. This is especially critical for variable magnetic fields and/or when the EEP is e.g. moved rapidly in and out from the SOL by a probe manipulator, staying only for short times inside it, as it is a necessity in MSTs.

- Since there is a voltage-drop along a current-carrying wire loop, such an EEP is not an equipotential surface. Therefore measurements of the floating potential are ambiguous.

- A wire loop EEP needs two long wires and an external power supply or battery for the heating current. Especially in the case of large experiments, such as MSTs, the cable connections to the power supply can be very long. This increases the capacity of the circuit, thereby reducing the temporal resolution [21].

To circumvent the problems of electrically heated wire-EEPs, various efforts were made to develop EEPs that can be heated indirectly. Fink et al. [86] developed an EEP in the form of a narrow cylinder of $\mathrm{LaB}_{6}$, closed on one side, heated by a separate filament inside. Ineluctably this probe construction became rather voluminous.

We have successfully developed various types of laserheated EEPs [36,69,73-75]. Inevitably the construction of such an EEP is more intricate than of a conventional wire EEP, but our latest development of a laser-heated EEP was not larger than a one-pin CLP and could be moved radially while being heated steadily by a focused IR laser beam [73-75]. The probe collector consisted of just a $\mathrm{LaB}_{6}$ pin of $1 \mathrm{~mm}$ diameter and $2 \mathrm{~mm}$ length.

In spite of the obvious advantages of a laser-heated EEP such a probe would be too intricate for the use on an MST 
probe manipulator. Aside from any possible interaction of the heating laser beam with the plasma to be investigated, it would be extremely complicated to construct a lasersystem which would follow a probe pin on a probe head from the retracted rest position into the plasmas during its insertion into the SOL by the probe manipulator. Also an EEP that is heated by a focused laser beam solely in the rest position is no good choice since our considerations have shown that the temperature of the probe pin will decrease to non-emissive temperatures during the insertion of the probe into the plasma [87]. And even though it will be heated there again by the heat flux of the plasma, possibly becoming self-emitting $[85,86,88,89]$, the interruption of the electron emission during insertion is not what we want.

\subsection{Robust EEP for hot plasmas (deep SOL)}

Schneider et al. developed a robust EEP consisting of a "loop" of Highly Orientated Pyrolytic Graphite (HOPG) on which an HOPG probe pin is mounted [24,90-92] (see Fig. 3). Only the tip of this pin will be in contact with the plasma and will be covered by a layer of titanium carbide. More details on the construction will be published later [24].

This EEP is made of Highly Orientated Pyrolytic Graphite (HOPG), which has strongly different values of electric resistivity and heat conduction in directions perpendicular to each other:

- electric resistivity along principal axis (001): $0.25 \times 10^{-2} \Omega \mathrm{m}$;

- electric resistivity along the layer plane (002): $5 \times 10^{-7} \Omega \mathrm{m}$;

- thermal conductivity along principal axis (001): $8 \mathrm{~W} \mathrm{~m}^{-1} \mathrm{~K}^{-1}$;

- thermal conductivity along the layer plane (002): $1800 \mathrm{~W} \mathrm{~m}^{-1} \mathrm{~K}^{-1}$.

The two "legs" of the HOPG "loop" are adjusted parallel to the layer plane (002) so that the heating current through the legs will not produce much heat there. In the crosslink between the two legs the layer direction is 001 with an electric resistivity 5000 times higher so that in this short part most of the electric heating will take place. In the centre of this cross link the actual probe pin is inserted in a hole. The crystal layer in this pin is directed in such a way (002) that the heat conductivity along its axis is highest so that the heat produced in the crosslink will be transported easily towards the end of the pin.

This probe will eventually be inserted into the graphite case of the so-called New Probe Head (NPH) together with other diagnostic tools and only the last $3 \mathrm{~mm}$ of the pin will protrude from the front side of the graphite case. Further publications on the NPH will follow [93].

\section{Electron Screening Probes (ESP)}

\subsection{The Katsumata probe}

As mentioned above, an EPS can work properly only in strong magnetic fields since their principle is based on the

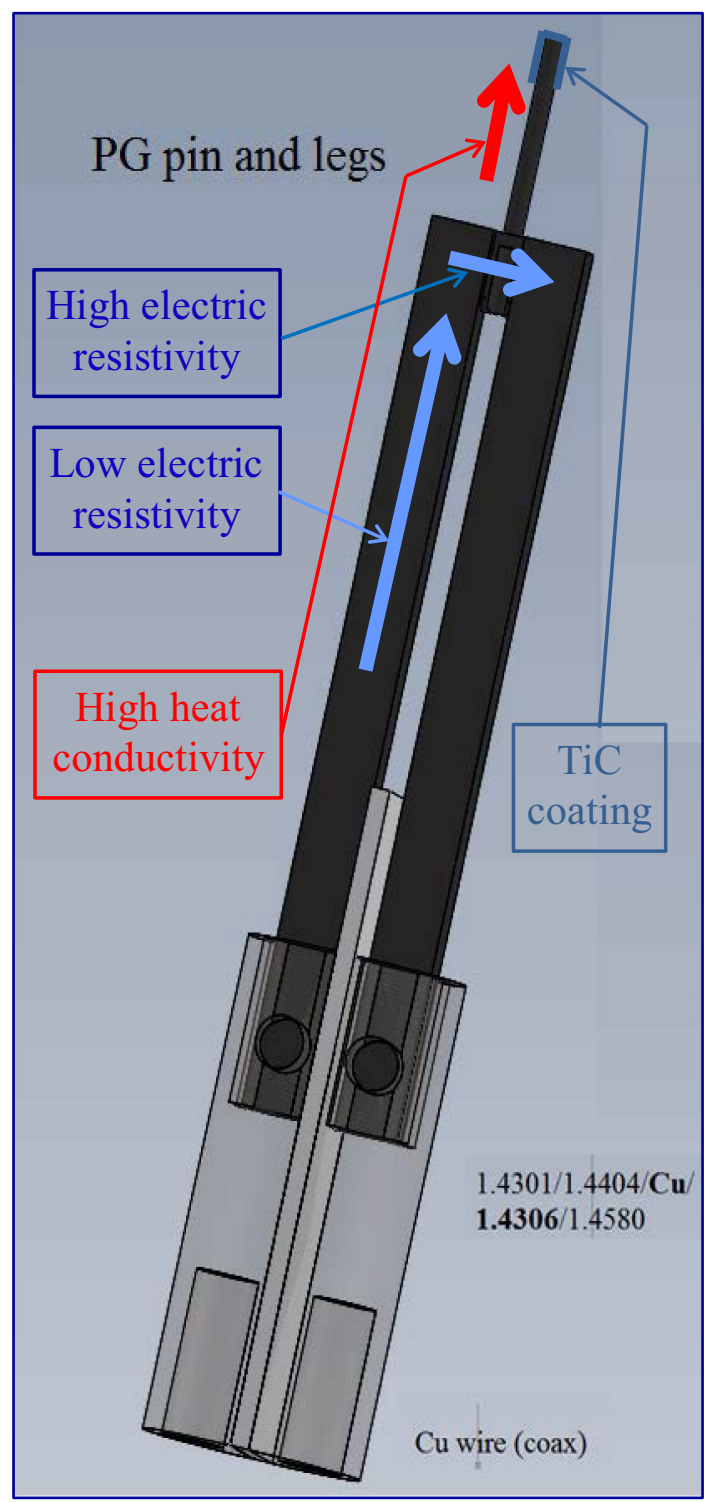

Fig. 3. Schematic presentation of the EEP of Highly Oriented Pyrolytic Graphite (HOPG) for usage in the deep SOL of MSTs (from Schneider et al. [24]). The blue arrows suggest the strongly different electric resistivity of HOPG in the two main directions of the graphite crystal lattice. The red arrow shows the direction of high heat conductivity from the HOPG "loop" upward to the actual probe pin whose tip will be covered by a layer of titanium carbide (see Tab. 1 in [24]).

strong difference between the gyro radii of electrons and ions in a conventional magnetized plasma. The gyro radius $r_{\mathrm{i}, \mathrm{e}}$ of an singly charged ion/electron in a magnetic field $B$ is usually given by the following relation:

$$
r_{\mathrm{i}, \mathrm{e}}=\frac{\mathrm{v}_{\mathrm{th} \mathrm{i}, \mathrm{e}}}{\Omega_{\mathrm{i}, \mathrm{e}}}=\frac{\sqrt{2 T_{\mathrm{i}, \mathrm{e}} m_{\mathrm{i}, \mathrm{e}}}}{e B} .
$$

Here $\mathrm{v}_{\text {th } \mathrm{i}, \mathrm{e}}$ is the thermal velocity of ion/electrons and $\Omega_{\mathrm{i}, \mathrm{e}}=e B / m_{\mathrm{i}, \mathrm{e}}$ is the cyclotron frequency of the particles. For equal temperatures $T_{\mathrm{i}} \cong T_{\mathrm{e}}$, the ratio between the gyro radii $r_{\mathrm{i}} / r_{\mathrm{e}}$ is given by $\sqrt{m_{\mathrm{i}} / m_{\mathrm{e}}}$, which comes down 


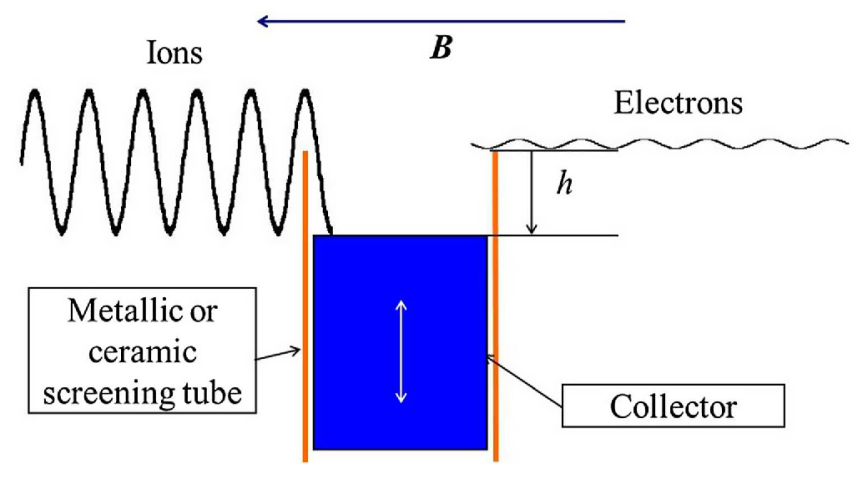

Fig. 4. Principle of a Katsumata probe $[29,30]$. Due to the strongly different gyro radii of electrons and ions in a magnetic field, in such a configuration the electrons can - ideally not reach the collector, whereas the ions can. By shifting the collector up and down inside the screening tube, the perpendicular energy distribution of the ions can be scanned. Due to drift effects, in reality also electrons can reach the collector, which is essential for using ESPs as PPPs.

to 43 or 61 for protium or deuterium, respectively. As we have seen above, for a typical SOL plasma of deuterium with $B=1 \mathrm{~T}$ and $T_{\mathrm{i}} \cong T_{\mathrm{e}} \cong 50 \mathrm{eV}$ the electron gyro radius $r_{\mathrm{e}} \cong 16.8 \mu \mathrm{m}$, while $r_{\mathrm{i}} \cong 1.02 \mathrm{~mm}$. For $T_{\mathrm{i}} \cong T_{\mathrm{e}} \cong 100 \mathrm{eV}$ we get $r_{\mathrm{e}} \cong 23.7 \mu \mathrm{m}$ and $r_{\mathrm{i}} \cong 1.44 \mathrm{~mm}$. Obviously, however, these values of the gyro radii are only average values since both the particle velocities and the pitch angle of the particles' velocity vectors with the magnetic field lines have distributions. While the particle velocities will more or less be Maxwell-distributed, the pitch angle can vary between $0^{\circ}$ and $90^{\circ}$.

The principle of a Katsumata probe [29,30], which all ESPs are based on, is shown in Figure 4 (see also [94-96]). We note that this principle is actually only described in Katsumata's latter work [30].

To screen off electrons from the collector, while not overly hamper the ions, its retraction depth $h$ inside the screening tube must obviously be larger than $2 r_{\mathrm{e}}$ but smaller than $2 r_{\mathrm{i}}$. We note that Katsumata called his probe "ion sensitive probe" since the probe was supposed to be sensitive only for ions. We, however, prefer to call such probes Electron-Screening Probes (ESP) since we try to realise an equality of the magnitudes of $j_{\mathrm{es}}$ and $j_{\text {is }}$ by screening off the major part of the electron current density.

\subsection{The Ball-Pen Probe (BPP)}

The fact that in spite of the geometrical screening effect, also some electrons can always reach the collector due to drift effects is the rationale of the BPP developed by Adámek et al. [25-27] (see Fig. 5). This fact makes it possible to realise the second principle to render an $I_{\mathrm{p}}-V_{\mathrm{p}}$ characteristic of a probe symmetric and its floating potential $V_{\mathrm{fl}, \mathrm{sp}}$ approximately equal to the plasma potential $\Phi_{\mathrm{pl}}$, as schematically shown in Figure 1 by the blue dotted line. In this case the relation between $V_{\mathrm{fl}, \mathrm{sp}}$ of the BPP (as one type of an ESP) and $\Phi_{\mathrm{pl}}$ becomes:

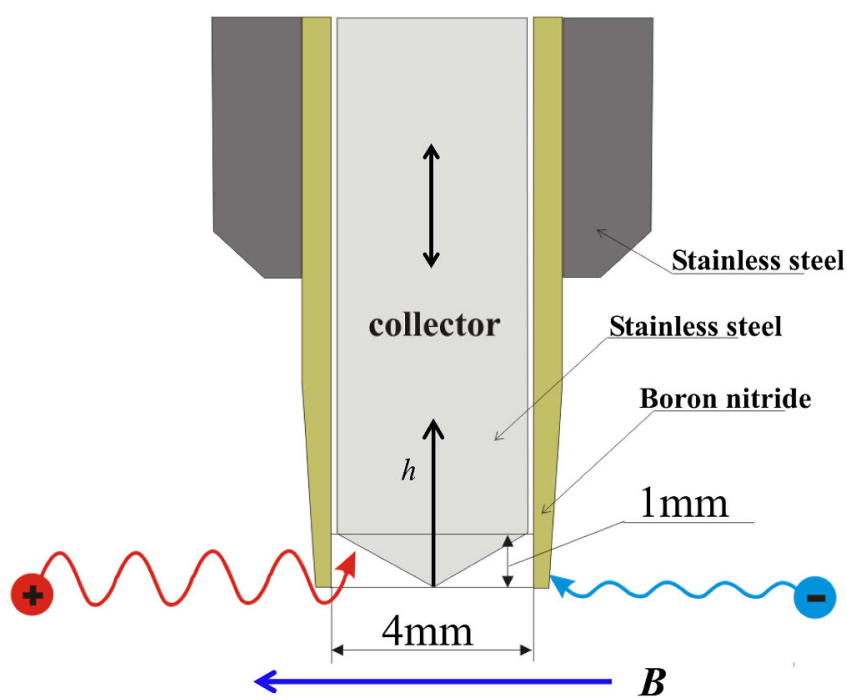

Fig. 5. Principle of a Ball-Pen Probe (BPP) as shown by Adámek et al. in $[25,26]$. In contrast to the Katsumata probe the screening tube is made of ceramic and the head of the collector is conical for a finer adjustment of the magnitudes of the effective electron and ion currents to the collector.

$$
\begin{aligned}
V_{\mathrm{fl}, \mathrm{sp}} & =\Phi_{\mathrm{pl}}-\frac{T}{e} \ln \left(\frac{\left|j_{\mathrm{es}} A_{\mathrm{pe}}(h)\right|}{\left|j_{\mathrm{is}} A_{\mathrm{pi}}(h)\right|}\right) ; \frac{\left|j_{\mathrm{es}} A_{\mathrm{pe}}(h)\right|}{\left|j_{\mathrm{is}} A_{\mathrm{pi}}(h)\right|}=1 \\
& \Rightarrow V_{\mathrm{fl}, \mathrm{sp}}=\Phi_{\mathrm{pl}} .
\end{aligned}
$$

By shifting the collector (see Fig. 5) in and out of the screening tube both (thus by varying $h$ ), the effective collecting areas of the BPP for electrons, $A_{\mathrm{ep}}$, and for ions, $A_{\text {ip }}$, can be varied over a wide range - though not completely independent from each other. When $h$ is made negative, i.e., when the collector starts protruding from the ceramic screening tube, the BPP will act as a usual CLP.

As we have seen in Section 1.2, only in very exotic plasmas the electron current density $\left|j_{\text {es }}\right|$ is not much larger than the ion current density $\left|j_{\text {is }}\right|$. And even differences of the effective collecting areas $A_{\mathrm{pe}}$ and $A_{\mathrm{pi}}$ for electron and ions, respectively, in strong magnetic fields will not alter this inequality very much (see Sect. 1.3). But with the $\mathrm{BPP}$, by varying $h$, for the first time $A_{\mathrm{pe}}$ and $A_{\mathrm{pi}}$ can be varied sufficiently so that the above mentioned equality of the electron and ion currents $\left|j_{\mathrm{es}} A_{\mathrm{pe}}(h)\right| \cong\left|j_{\text {is }} A_{\mathrm{pi}}(h)\right|$ can be achieved. It is noteworthy that Adámek et al.'s investigations showed that for many cases the actual value of $h$ has no great influence on the principle functionality of a BPP, i.e., in the CASTOR tokamak for instance, for $B=1.3 \mathrm{~T}$ and $T_{\mathrm{e}} \cong T_{\mathrm{i}} \cong 10 \mathrm{eV}, h$ could be varied between $0.5 \leq h \leq 2.0 \mathrm{~mm}$ while the floating potential $V_{\mathrm{fl}, \mathrm{sp}}$ remained around $\Phi_{\mathrm{pl}}[25]$.

The BPP has been used by Adámek et al. in various types of magnetised plasmas [25-27,85,96-117] and has proven its value many times, recently even in nonmagnetised plasmas [118].

Besides the BPP, two other types of ESPs have been developed to measure the plasma potential directly: these are plug probes $[119,120]$ and baffled probes [121-124]. Also these probes work only in strong magnetic fields, 


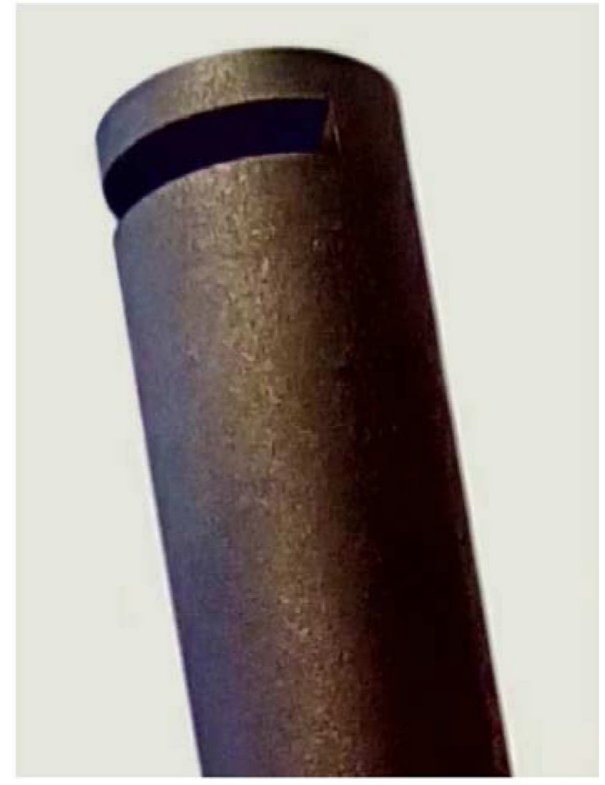

Fig. 6. BUnker Probe (BUP) of graphite (from Costea et al. [28]). The cylindrical piece has an outer diameter of $12 \mathrm{~mm}$ and an inner diameter of $8 \mathrm{~mm}$. It is closed on top and has a $2 \mathrm{~mm}$ wide slit which encompasses half the cylinder's circumference.

where there is a strong difference between the gyro radii of electrons and ions, utilizing special geometries to screen off the major part of the electron current from the probe collector to render the magnitude of the electron current approximately equal to that of the ion current. These probes have, however, not yet been used in toroidal fusion experiments, as far as we know.

\subsection{Bunker probe, type 1, BUP1}

One problem with a BPP is that it has to be aligned quite precisely perpendicularly to the magnetic field $\boldsymbol{B}$ to work properly. To avoid this drawback, Costea et al. [28], developed the so-called BUnker Probe (BUP), whose collector floats on the plasma potential for a large range of angles with respect to $\boldsymbol{B}$ (see Fig. 6).

Costea chose the name "Bunker probe" for its resemblance with a real bunker as it can still be found for instance on the island of Texel for Netherlands' coastal defence in WW II. In case of such a bunker the slit in the outer wall made it possible for a gun to pivot its barrel over a wide range to rake it with gunfire.

The slit in the BUP and the slant of the collector inside the cylindrical graphite case with respect to the axis of the cylinder make it possible that in principle for a range from $\beta=0^{\circ}$ to $90^{\circ}$ between the cylinder axis and $\boldsymbol{B}$, electrons are prevented from reaching the collector whereas ions can reach it. This is shown schematically in Figure 7 [28].

In a comprehensive comparison with a BPP, carried out in the Linear Magnetic Plasma Device (LMPD) at the Jožef Stefan Institute, Ljubljana, Slovenia, [28], it could be shown that the floating potential $V_{\mathrm{f}, \text {,sp,BUP }}$ of the BUP remains constant at least for an angular range of $30^{\circ} \leq \beta \leq 90^{\circ}$ with respect to $\boldsymbol{B}$ whereas the floating potential $\bar{V}_{\mathrm{fl}, \mathrm{sp}, \mathrm{BPP}}$ of the BPP started to become more positive for angles below $60^{\circ}$, approaching the normal floating potential $V_{\mathrm{fl}, \mathrm{cp}}$ of a CLP as the opening of the BPP became directly accessible for electrons. The magnetic field of the LMPD was varied between 0.1 and $0.3 \mathrm{~T}$.

\subsection{Bunker probe, type 2, BUP2}

To circumvent the limitation of BUP1 that it can register only particles from one side (see Fig. 7), in the meantime Costea [125] carried on the development of this type of probe to make it sensitive to particles from all sides. Figure 8 (Fig. 3.9 in [125]) shows the latest design of BUP2. Preliminary results of tests of the BUP2 in the LMPD, Jožef Stefan Institute, Ljubljana, Slovenia, and comparison with a CLP are also shown (see Figs. 9 and 3.11 in [125]).

By virtually rotating the probe around the slit, a design has been found which allows the probe to collect charged particles from a $2 \pi$ solid angle in front of the probe. In this new configuration, the slit turns into an orifice and the slanted collector turns into a ring with triangular crosssection (see Fig. 8, taken from [125]).

In the $I_{\mathrm{p}}-V_{\mathrm{p}}$ characteristics of BUP2 Costea observed that the electron current to the collector of BUP2 is considerably reduced, to the point where it is comparable to the ion current, regardless of the orientation of the probe with respect to $\boldsymbol{B}$. The $I_{\mathrm{p}}-V_{\mathrm{p}}$ characteristics of a cylindrical CLP Langmuir probe are shown in the bottom-left graph of Figure 9 for comparison. The collected ion current of BUP2 is small for the lower values of $B$ (blue curves) but the ion collection improves for higher values of $B$ (red curves), suggesting a geometrical dependence of BUP2 on the ion gyro radius. By comparing the ion saturation currents of BUP2 and the Langmuir probe (LP), it was observed that the collected ion current of BUP2 is one order of magnitude smaller than of the CLP, suggesting that the chosen sizes of the orifice or of BUP2 are not yet optimal for the trajectories of charged particles in the investigated magnetized plasma of the LMPD.

By comparing the averaged readouts of the floating potential (in Fig. 9 called $V_{\mathrm{f}}$ ) of BUP2 with the values of the floating potentials and the plasma potentials obtained from the $I_{\mathrm{p}}-V_{\mathrm{p}}$ characteristics of the Langmuir probe, it was observed that the floating potential of BUP2 is not close to the plasma potential even though the electron current has been reduced considerably to being comparable in magnitude with the ion current. This effect can be due to the screening also of ions as it can be seen from the magnitude of the ion saturation current from the $I_{\mathrm{p}}-V_{\mathrm{p}}$ characteristics of BUP2 compared to the ones from the Langmuir probe. The screening of ions will be investigated in future constructions of BUP2 and particle-in-cell simulations will be carried out in order to improve its design.

It can be expected that the design of the BUP2 (see Fig. 9, taken from [125]) will also be suitable for flushmounting the probe into the wall of an MST or into divertor tiles, where particularly in case the magnetic field is usually not parallel to the wall. Further investigations of this type of PPP are under way. 


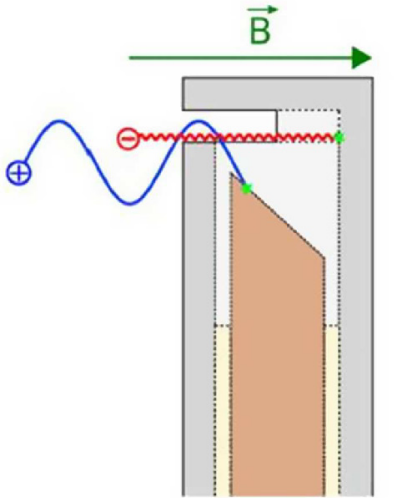

a) perpendicular

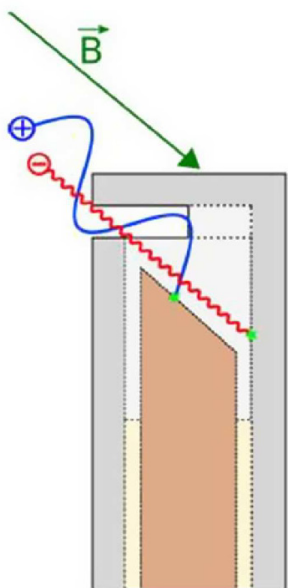

b) oblique

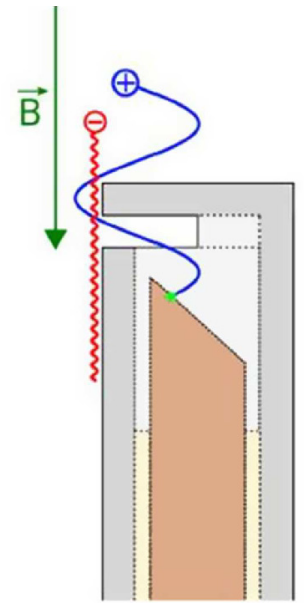

c) parallel

Fig. 7. Representation of the Bunker probe (cross-section) and trajectories of magnetically confined ions (blue, + ) and electrons $($ red, -$)$ for different orientations of the probe with respect to the magnetic field ( $\boldsymbol{B}$, green arrow) (from Costea et al. [28]); (a) $\beta=90^{\circ}$, (b) $\beta=45^{\circ}$, (c) $\beta=0^{\circ}$.
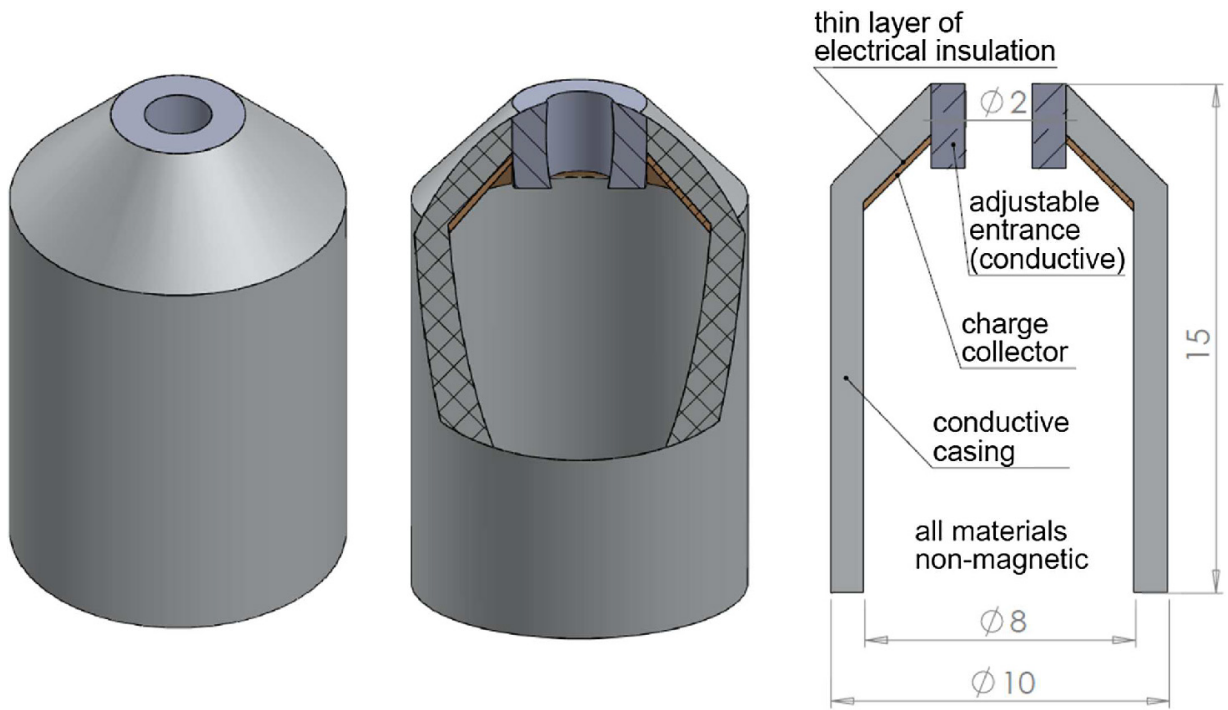

Fig. 8. Representation of the Bunker probe, type 2, all measures are in mm. The casing and the charge collector are of aluminium and electrically separated from each other by Kapton tape. The probe's orifice has a diameter of $1 \mathrm{~mm}$ for an improved screening of the electrons (from [125]).

\section{Conclusion}

While the plasma potential is arguably the most important plasma parameter, it is not easy to measure it with the necessary good time and spatial resolution. Especially for investigations of turbulence and transport in hot plasmas a reliable knowledge of the electric field would be highly desirable, for which the spatial profile of the plasma potential should be determined with sufficient reliability. Plasma probes are relatively easy and inexpensive diagnostic tools, but from conventional Cold Langmuir Probes the plasma potential can only be derived indirectly and only in a Maxwellian plasma.

The floating potential of a probe is the most easily measured parameter, also with high temporal and spatial reso- lution. On the other hand, the floating potential of a Cold Langmuir Probe is of not much use since it depends also on the electron temperature which in turn is not known reliably enough or shows strong spatial and temporal variations. We have therefore directed our efforts to probes whose floating potential is equal, or at least close, to the plasma potential. This review presents recent developments of such Plasma Potential Probes of which two types appear promising: Electron-Emissive Probes and Electron Screening Probes. Both types have the potential to produce a symmetric current-voltage characteristic which, at the same time, means that their floating potential is in principal equal to the plasma potential. The former type of probe, the Electron-Emissive Probe, operates also in non-Maxwellian plasmas, while the latter type of probe, 

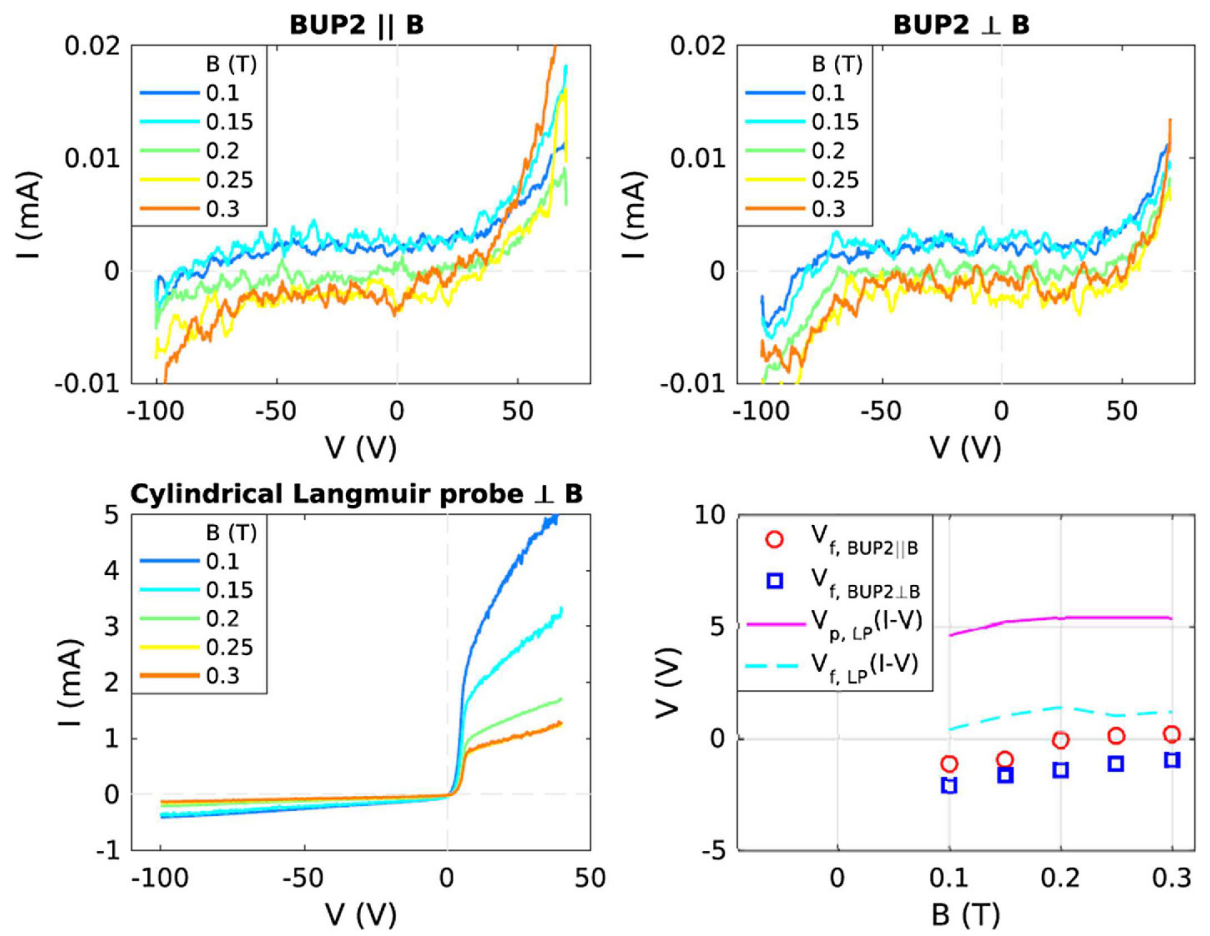

Fig. 9. Top graphs: current-voltage characteristics (here $I-V$ ) of BUP2 for various values of $B$ when oriented parallel (left graph) or perpendicular (right graph) to $\boldsymbol{B}$. Bottom left: $I-V$ characteristics of a cylindrical CLP oriented perpendicular to $\boldsymbol{B}$. Bottom right: averaged readouts of the floating potential (here called $V_{\mathrm{f}}$ ) of BUP2 when oriented parallel and perpendicular to $\boldsymbol{B}$ (red circles and blue squares, respectively) and the floating and plasma potentials extracted from the $I-V$ characteristics of the CLP (dashed line and continuous line, respectively), for various values of $B$ (from [125]).

the Electron Screening Probe, usually requires a strong magnetic field to work properly.

As for Electron-Emissive Probes we have succeeded to design a type which, on one side, is very robust to withstand also strong particle fluxes, while on the other side it can produce a very strong emission current making it applicable also in hot plasmas, such as for instance, the edge region of toroidal fusion experiments or hazardous technical deposition plasmas $[23,24,90]$.

As for Electron Screening Probes we were successful to develop new types which do not require a very precise alignment with the magnetic field, which makes them applicable in devices with complicated magnetic field configurations or quickly varying magnetic fields [28]. Magnetic island formation in tokamaks or stellarators as such are examples where such probes can find their best fields of application.

Open access funding provided by University of Innsbruck and Medical University of Innsbruck. This work has been carried out within the framework of the EUROfusion Consortium and has received funding from the EURATOM research and training programme 2014-2018 under Grant Agreement No. 633053. The views and opinions expressed herein do not necessarily reflect those of the European Commission. Bernd Schneider has been a fellow of the Friedrich Schiedel Foundation for Energy Technology. This work was also supported by the Commission for the Coordination of Nuclear Fusion Research in Austria (KKKÖ - Austrian Academy of Sciences), by the Tiroler Wissenschaftsförderung, by the Bilateral Scientific-Technical project SI 09/2016 between Austria and Slovenia and by the CEEPUS Network AT-0063.

\section{Author contribution statement}

C. I. conceived the presented idea and wrote the manuscript with support from R. Sch. B. S. S. developed and constructed the Electron-Emissive Probe (EEP) and carried out the first tests of it. S. C. developed the BUnker Probe (BUP), tested it and proved its experimental suitability. O. V. contributed to the data acquisition system which will be used. J. K. and T. G. collaborated and contributed to the tests of the BUP by S. C., V. N. and J. J. R. made essential contributions to the formalism of the equations. N. V. and M. S. contributed to the discussion of the presented results and developments and to the composition of the manuscript. R. St. made essential contributions to the development of the EEP and hardware for the data acquisition. All authors contributed to the discussion of the presented results and developments and to the composition of the manuscript.

Open Access This is an open access article distributed under the terms of the Creative Commons Attribution License (http://creativecommons.org/licenses/by/4.0/), which permits unrestricted use, distribution, and reproduction in any medium, provided the original work is properly cited. 


\section{References}

1. W. Crookes, Radiant matter: A Resume of the principal lectures and papers of Prof. William Crookes on the fourth state of matter, (James W. Queen \& Co, Philadelphia, PA, USA, 1881)

2. W. Crookes, On Radiant Matter, 1880, http: //www. electrotherapymuseum.com/Library/ SirWilliamCrookes/index.html

3. I. Langmuir, J. Franklin Inst. CXCVI, 1 (1923)

4. I. Langmuir, in The Collected Works of Irving Langmuir, edited by C. Guy Suits (Pergamon Press, 1961), Vol. 5, pp. $1-10$

5. I. Langmuir, Phys. Rev. 33, 954 (1929)

6. J. Stark, T. Retschinsky, Ann. Phys. 323, 213 (1905)

7. C. Ionita, V. Naulin, F. Mehlmann, J.J. Rasmussen, H.W. Müller, R. Schrittwieser, V. Rohde, A.H. Nielsen, Ch. Maszl, P. Balan, A. Herrmann, Nucl. Fusion 53, 043021 (2013)

8. F.F. Chen, Electric probes, in Plasma Diagnostic Techniques, edited by R.H. Huddlestone, S.L. Leonard (Academic Press, New York, London, 1965), Chap. 4, pp. 113-200

9. L. Schott, Electric probes, in Plasma Diagnostics, edited by W. Lochte-Holtgreven (North-Holland Publishing Company, Amsterdam, 1968), Chap. 11, pp. 668-731

10. I.H. Hutchinson, in Principles of Plasma Diagnostics, Second Edn (Cambridge University Press, 2002), pp. $55-103$

11. N. Hershkowitz, How Langmuir probes work, in Plasma Diagnostics, (Discharge Parameters and Chemistry), edited by O. Auciello, D.L. Flamm (Academic Press, 1989), Chap. 3, pp. 113-183

12. https://www.britannica.com/science/ protium-isotope

13. D. Bohm, in The characteristics of electric discharges in magnetic field, edited by A. Guthry, R.K. Wakerlind (MacGraw-Hill, New York, 1949), Chap. 3, p. 77

14. J.E. Allen, J. Phys. D: Appl. Phys 9, 2331 (1976)

15. K.-U. Riemann, J. Phys. D: Appl. Phys 24, 493 (1991)

16. C. Charles, Plasma Sources Sci. Technol. 16, R1 (2007)

17. R. Schrittwieser, in Fourth Symposium on Double Layers and Other Nonlinear Potential Structures in Plasmas Innsbruck, Austria, July 6-8, 1992 (Proceedings, World Scientific Publishing Company, Singapore, 1993) P. 498

18. H.W. Müller, J. Adamek, J. Horacek, C. Ionita, F. Mehlmann, V. Rohde, R. Schrittwieser, Contrib. Plasma Phys. 50, 847 (2010)

19. C. Ionita, J. Grünwald, Ch. Maszl, R. Stärz, M. Čerček, B. Fonda, T. Gyergyek, G. Filipič, J. Kovačič, C. Silva, H. Figueiredo, T. Windisch, O. Grulke, T. Klinger, R. Schrittwieser, Contrib. Plasma Phys. 51, 264 (2011)

20. S. Dushman, Phys. Rev. 21, 623 (1923)

21. S. Iizuka, P. Michelsen, J.J. Rasmussen, R. Schrittwieser, R. Hatakeyama, K. Saeki, N. Sato, J. Phys. E: Sci. Instrum. 14, 1291 (1981)

22. R.W. Schrittwieser, C. Ionita, C.T. Teodorescu-Soare, O. Vasilovici, S. Gurlui, S.A. Irimiciuc, D.G. Dimitriu, Phys. Scr. 92, 044001 (2017)

23. B.S. Schneider, S. Costea, C. Ionita, R. Schrittwieser, V. Naulin, J.J. Rasmussen, R. Stärz, N. Vianello, J. Kovacic, T. Gyergyek, Proc. Science, electronic ver- sion, http://pos.sissa.it/archive/conferences/240/ 072/ECPD2015_072.pdf (2015)

24. B.S. Schneider, S. Costea, C. Ionita, O. Vasilovici, R. Stärz, J. Kovačič, T. Gyergyek, V. Naulin, J.J. Rasmussen, N. Vianello, M. Spolaore, R. Schrittwieser, Rev. Sci. Instrum. (2018), in preparation

25. J. Adámek, J. Stöckel, M. Hron, J. Ryszawy, M. Tichý, R. Schrittwieser, C. Ionita, P. Balan, E. Martines, G. Van Oost, Czech. J. Phys. 54, C95 (2004)

26. J. Adámek, J. Stöckel, I. Ďuran, M. Hron, R. Pánek, M. Tichý, R. Schrittwieser, C. Ionita, P. Balan, E. Martines, G. Van Oost, Czech. J. Phys. 55, 235 (2005)

27. R. Schrittwieser, C. Ionita, J. Adámek, J. Brotánková, J. Stöckel, E. Martines, C. Costin, G. Popa, L. van de Peppel, G. Van Oost, Czech. J. Phys. 56, B145 (2006)

28. S. Costea, B. Fonda, J. Kovacic, T. Gyergyek, B. Schneider, R. Schrittwieser, C. Ionita, Rev. Sci. Instrum. 87, 053510 (2016)

29. I. Katsumata, M. Okazaki, Jpn. J. Appl. Phys. 6, 123 (1967)

30. I. Katsumata, Contrib. Plasma Phys. 36, 73 (1996)

31. N. Rynn, N. D’Angelo, Rev. Sci. Instrum. 31, 1326 (1960)

32. R.W. Motley, Q-Machines (Academic Press, 1975)

33. A. Marek, I. Picková, P. Kudrna, M. Tichý, R.P. Apetrei, S.B. Olenici, R. Gstrein, R. Schrittwieser, C. Ionita, Czech. J. Phys. 56, B932 (2006)

34. A. Marek, M. Jilek, I. Pickova, P. Kudrna, M. Tichy, R. Schrittwieser, C. Ionita, Contrib. Plasma Phys. 48, 491 (2008)

35. R. Schrittwieser, J. Adámek, P. Balan, M. Hron, C. Ionita, K. Jakubka, L. Kryška, E. Martines, J. Stöckel, M. Tichý, G. Van Oost, Plasma Phys. Contr. Fusion 44, 567 (2002)

36. R. Schrittwieser, C. Ionita, P. Balan, R. Gstrein, O. Grulke, T. Windisch, C. Brandt, T. Klinger, R. Madani, G. Amarandei, A. Sarma, Rev. Sci. Instrum. 79, 083508 (2008)

37. J.M. Sellen Jr., W. Bernstein, R.F. Kellen, Rev. Sci. Instrum. 36, 316 (1965)

38. R.F. Kemp, J.M. Sellen Jr., Rev. Sci. Instrum. 37, 455 (1966)

39. J.R. Smith, N. Hershkowitz, P. Coakley, Rev. Sci. Instrum. 50, 210 (1979)

40. M.H. Cho, C. Chan, N. Hershkowitz, T. Intrator, Rev. Sci. Instrum. 55, 631 (1984)

41. E.Y. Wang, T. Intrator, N. Hershkowitz, Rev. Sci. Instrum. 56, 519 (1985)

42. E.Y. Wang, N. Hershkowitz, T. Intrator, C. Forest, Rev. Sci. Instrum. 57, 2425 (1986)

43. D. Diebold, N. Hershkowitz, A.D. Bailey III, M.H. Cho, T. Intrator, Rev. Sci. Instrum. 59, 270 (1988)

44. N. Hershkowitz, M.H. Cho, J. Vac. Sci. Technol. A 6, 2054 (1988)

45. T. Lho, N. Hershkowitz, G.-H. Kim, Rev. Sci. Instrum. 71, 403 (2000)

46. J.P. Sheehan, N. Hershkowitz, Plasma Sources Sci. Technol. 20, 063001 (2011)

47. L. Oksuz, N. Hershkowitz, Phys. Rev. Lett. 89, 145001 (2002)

48. E.H. Wilson, J. Jeong, N. Hershkowitz, Rev. Sci. Instrum. 73, 2033 (2002)

49. S. Yan, H. Kamal, J. Amundson, N. Hershkowitz, Rev. Sci. Instrum. 67, 4130 (1996) 
50. J.P. Sheehan, Y. Raitses, N. Hershkowitz, M. McDonald, J. Propul. Power 33, 614 (2017)

51. P. Balan, J.A. Cabral, R. Schrittwieser, H.F.C. Figueiredo, H. Fernandes, C. Ioniţă, C. Varandas, J. Adámek, M. Hron, J. Stöckel, E. Martines, M. Tichý, G. Van Oost, Rev. Sci. Instrum. 74, 1583 (2003)

52. C. Ioniţă, P. Balan, R. Schrittwieser, H.F.C. Figueiredo, R.M.O. Galvão, C. Silva, C.A.F. Varandas, Rev. Sci. Instrum. 75, 4331 (2004)

53. K. Hirao, K. Oyama, J. Geomagn. Geoelectr. 23, 47 (1971)

54. R.W. Motley, J. Appl. Phys. 43, 3711 (1972)

55. J.J. Schuss, R.R. Parker, J. Appl. Phys. 45, 4778 (1974)

56. R.L. Merlino, S.L. Cartier, J. Phys. D: Appl. Phys. 20, 1074 (1987).

57. A. Siebenförcher, R. Schrittwieser, Rev. Sci. Instrum. 67, 849 (1996)

58. K. Reinmüller, Contrib. Plasma Phys. 38, 7 (1998)

59. S. Takamura, M.Y. Ye, T. Kuwabara, N. Ohno, Phys. Plasmas 5, 2151 (1998)

60. M.Y. Ye, S. Takamura, Phys. Plasmas 7, 3457 (2000)

61. R. Schrittwieser, C. Ioniţă, P.C. Balan, J.A. Cabral, H.F.C. Figueiredo, V. Pohoaţă, C. Varandas, Contrib. Plasma Phys. 41, 494 (2001)

62. V.I. Demidov, S.V. Ratynskaia, K. Rypdal, Rev. Sci. Instrum. 73, 3409 (2002)

63. A. Matsubara, T. Sugimoto, T. Shibuya, K. Kawamura, S. Sudo, K. Sato, J. Nucl. Mat. 313-316, 720 (2003)

64. H. Himura, M. Fukao, H. Wakabayashi, Z. Yoshida, Rev. Sci. Instrum. 74, 4658 (2003)

65. S. Takamura, N. Ohno, M.Y. Ye, T. Kuwabara, Contrib. Plasma Phys. 44, 126 (2004)

66. K.S. Chung, G.Y. Kwak, Y.S. Choi, M.J. Lee, J.G. Bak, M. Kwon, Rev. Sci. Instrum. 72, 4299 (2004)

67. N. Mahdizadeh, F. Greiner, M. Ramisch, U. Stroth, W. Guttenfelder, C. Lechte, K. Rahbarnia, Plasma Phys. Contr. Fusion 47, 569 (2005)

68. R. McWilliams, D. Edrich, Contrib. Plasma Phys. 46, 411 (2006)

69. R. Schrittwieser, A. Sarma, G. Amarandei, C. Ionita, T. Klinger, O. Grulke, A. Vogelsang, T. Windisch, Phys. Scr. T123, 94 (2006)

70. K. Kusaba, H. Shindo, Rev. Sci. Instrum. 78, 123503 (2007)

71. T. Gyergyek, M. Cercek, Eur. Phys. J. D 42, 441 (2007)

72. R. Schrittwieser, C. Ionita, P. Balan, C. Silva, H. Figueiredo, C.A.F. Varandas, J. Juul Rasmussen, V. Naulin, Plasma Phys. Control. Fusion 50, 055004 (2008)

73. C. Ionita, P. Balan, T. Windisch, C. Brandt, O. Grulke, T. Klinger, R. Schrittwieser, Contrib. Plasma Phys. 48, 453 (2008)

74. R.W. Schrittwieser, R. Stärz, C. Ionita, R. Gstrein, T. Windisch, O. Grulke, T. Klinger, J. Plasma Fusion Res. Ser. 8, 632 (2009)

75. R. Schrittwieser, C. Ionita, K. Rahbarnia, J. Gruenwald, T. Windisch, R. Stärz, O. Grulke, T. Klinger, Contrib. Plasma Phys. 53, 92 (2013)

76. A. Fruchtman, D. Zoler, G. Makrinich, Phys. Rev. E 84, 025402(R) (2011)

77. X. Chen, G. Sanchez-Arriaga, Phys. Plasmas 24, 023504 (2017)

78. G.L. Delzanno, X.-Z. Tang, Phys. Rev. Lett. 113, 035002 (2014)
79. B. Lipschultz, D.A. Pappas, B. LaBombard, J.E. Rice, D. Smith, S.J. Wukitch, Nucl. Fusion 41, 585 (2001)

80. http://www.iter.org/

81. N. Schupfer, D.D. Tskhakaya sr., R. Khanal, S. Kuhn, F. Aumayr., S. Figueira da Silva, H.P. Winter, Plasma Phys. Control. Fusion 48, 1093 (2006)

82. M.D. Campanell, M.V. Umansky, Phys. Rev. Lett. 116, 085003 (2016)

83. B.F. Kraus, Y. Raitses, Phys. Plasmas 25, 030701 (2018)

84. T. Gyergyek, J. Kovačič, Contrib. Plasma Phys. 53, 189 (2013)

85. J. Adámek, J. Horacek, J. Seidl, H.W. Müller, R. Schrittwieser, F. Mehlmann, P. Vondracek, S. Ptak, Contrib. Plasma Phys. 54, 279 (2014)

86. M.A. Fink, M. Endler, T. Klinger, Contrib. Plasma Phys. 44, 668 (2004)

87. F. Mehlmann, Private Communication (2012)

88. N. Hershkowitz, B. Nelson, J. Pew, D. Gates, Rev. Sci. Instrum. 54, 29 (1983)

89. V. Rohde, M. Laux, P. Bachmann, A. Herrmann, M. Weinlich M., J. Nucl. Mat. 241-243, 712 (1997)

90. B.S. Schneider, S. Costea, C. Ionita, R. Schrittwieser, V. Naulin, J.J. Rasmussen, R. Stärz, N. Vianello, J. Kovacic, T. Gyergyek, Indirectly heated strong and robust emissive probe for dense and hot plasmas, in $X X X I I^{\text {th }}$ Int. Conf. Phenomena in Ionized Gases (ICPIG) Iasi, Romania, 26-31 July 2015 (2015), P1.36.

91. B.S. Schneider, S. Costea, C. Ionita, R. Schrittwieser, V. Naulin, J.J. Rasmussen, N. Vianello, M. Spolaore, J. Kovačič, T. Gyergyek, R. Stärz, Advanced probe for transport measurements in Medium-Size Tokamaks, in $29^{\text {th }}$ Symp. Fusion Techn. (SOFT) Prague, Czech Republic, 5-9 September 2016, Book of Abstracts (Institute of Plasma Physics, Czech Academy of Sciences, 2016), P4.069, p. 716

92. B.S. Schneider, N. Vianello, M. Spolaore, V. Naulin, J.J. Rasmussen, R. Stärz, J. Kovačič, T. Gyergyek, S. Costea, C. Ionita, R. Schrittwieser, Tsv.K. Popov, Multi-diagnostic probe head for near-wall electric and magnetic measurements in medium-size tokamaks, in $44^{\text {th }}$ European Physical Society (EPS) Conf. Plasma Phys. Belfast, Northern Ireland, UK, 2630 June 2017, (2017) P4.105, http://ocs.ciemat.es/ EPS2017ABS/pdf/P4.105.pdf

93. B.S. Schneider, C. Ionita, S. Costea, O. Vasilovici, J. Kovačič, T. Gyergyek, B. Končar, M. Draksler, R. Nem, V. Naulin, J.J. Rasmussen, M. Spolaore, N. Vianello, R. Stärz, A. Herrmann, R. Schrittwieser, Plasma Phys. Contr. Fusion, 61, 054004 (2019)

94. P. Balan, R. Schrittwieser, J. Adámek, O. Bařina, P. De Beule, I. Ďuran, J.P. Gunn, R. Hrach, M. Hron, C. Ionita, E. Martines, R. Pánek, J. Stöckel, G. Van Den Berge, G. Van Oost, T. Van Rompuy, M. Vicher, Contrib. Plasma Phys. 44, 683 (2004)

95. J.P. Gunn, R. Schrittwieser, P. Balan, C. Ionita, J. Stöckel, J. Adámek, I. Ďuran, M. Hron, R. Pánek, O. Bařina, R. Hrach, M. Vicher, G. Van Oost, T. Van Rompuy, E. Martines, Rev. Sci. Instrum. 75, 4328 (2004)

96. J. Adamek, M. Kocan, R. Panek, J.P. Gunn, E. Martines, J. Stöckel, C. Ionita, G. Popa, C. Costin, J. Brotankova, R. Schrittwieser, G. Van Oost, Contrib. Plasma Phys. 48, 395 (2008) 
97. J. Stöckel, J. Adámek, P. Balan, O. Bilyk, J. Brotánková, R. Dejarnac, P. Devynck, I. Duran, J.P. Gunn, M. Hron, J. Horacek, C. Ionita, M. Kocan, E. Martines, R. Panek, P. Peleman, R. Schrittwieser, G. Van Oost, F. Zacek, J. Phys.: Conf. Ser. 63, 012001 (2007)

98. J. Adámek, J. Stöckel, H. Horacek, V. Rohde, H.W. Müller, A. Herrmann, C. Ionita, F. Mehlmann, J. Brotankova, R. Schrittwieser, J. Nucl. Mat. 390-391, 1114 (2009)

99. M. Komm, J. Adámek, Z. Pekárek, R. Pánek, Contrib. Plasma Phys. 50, 814 (2010)

100. J. Horaček, J. Adámek, H.W. Müller, J. Seidl, A.H. Nielsen, V. Rohde, F. Mehlmann, C. Ionita, E. Havlíčková, Nucl. Fusion 50, 105001 (2010)

101. J. Adámek, V. Rohde, H.W. Müller, B. Kurzan, C. Ionita, R. Schrittwieser, F. Mehlmann, J. Stöckel, J. Horacek, V. Weinzettl, Contrib. Plasma Phys. 50, 854 (2010)

102. H.W. Müller, J. Adámek, R. Cavazzana, G. Conway, J.C. Fuchs, J.P. Gunn, A. Herrmann, J. Horacek, C. Ionita, A. Kallenbach, M. Kocan, M. Maraschek, Ch. Maszl, F. Mehlmann, B. Nold, M. Peterka, V. Rohde, J. Schweinzer, R. Schrittwieser, N. Vianello, E. Wolfrum, M. Zuin, Nucl. Fusion 51, 073023 (2011)

103. M. Komm, J. Adámek, R. Dejarnac, J.P. Gunn, Z. Pekarek, Plasma Phys. Control. Fusion 53, 015005 (2011)

104. J. Adámek, M. Peterka, T. Gyergyek, P. Kudrna, M. Tichý, Nukleonika 57, 297 (2012)

105. J. Adámek, M. Peterka, T. Gyergyek, P. Kudrna, M. Ramisch, U. Stroth, J. Cavalier, M. Tichý, Contrib. Plasma Phys. 53, 39 (2013)

106. M. Zanáška, J. Adámek, M. Peterka, P. Kudrna, M. Tichý, Phys. Plasmas 22, 033516 (2015)

107. R. Pánek, J. Adámek, M. Aftanas, P. Bílková, P. Böhm, F. Brochard, P. Cahyna, J. Cavalier, R. Dejarnac, M. Dimitrova, O. Grover, J. Harrison, P. Háček, J. Havlíček, A. Havránek, J. Horáček, M. Hron, M. Imríšek, F. Janky, A. Kirk, M. Komm, K. Kovařík, J. Krbec, L. Kripner, T. Markovič, K. Mitošinková, J. Mlynár̆, D. Naydenkova, M. Peterka, J. Seidl, J. Stöckel, E. Štefániková, M. Tomeš, J. Urban, P. Vondráček, M. Varavin, J. Varju, V. Weinzettl, J. Zajac, COMPASS team, Plasma Phys. Control. Fusion 58, 014015 (2016)

108. P. Ondac, J. Horaček, J. Seidl, P. Vondrácek, H.W. Müller, J. Adámek, A.H. Nielsen, Acta Polytech. 55, 128 (2015)

109. N.R. Walkden, J. Adámek, S. Allan, B.D. Dudson, S. Elmore, G. Fishpool, J. Harrison, A. Kirk, M. Komm, Rev. Sci. Instrum. 86, 023510 (2015)

110. C. Silva, J. Adámek, H. Fernandes, H. Figueiredo, Plasma Phys. Control. Fusion 57, 025003 (2015)

111. J. Adámek, H.W. Müller, C. Silva, R. Schrittwieser, C. Ionita, F. Mehlmann, S. Costea, J. Horacek, B. Kurzan, P. Bilkova, P. Böhm, M. Aftanas,
P. Vondracek, J. Stöckel, R. Panek, H. Fernandes, H. Figueiredo, Rev. Sci. Instrum. 87, 043510 (2016)

112. M. Dimitrova, Tsv.K. Popov, J. Adamek, J. Kovačič, P. Ivanova, E. Hasan, D. López-Bruna, J. Seidl, P. Vondráček, R. Dejarnac, J. Stöckel, M. Imríšek, R. Panek, Plasma Phys. Control. Fusion 59, 125001 (2017)

113. M. Spolaore, K. Kovařŕk, J. Stöckel, J. Adámek, R. Dejarnac, I. Ďuran, M. Komm, T. Markovic, E. Martines, R. Panek, J. Seidl, N. Vianello, Nucl. Mat. Energy 12, 844 (2017)

114. V. Weinzettl, J. Adámek, M. Berta, P. Bilkova, O. Bogar, P. Bohm, J. Cavalier, R. Dejarnac, M. Dimitrova, O. Ficker, D. Fridrich, O. Grover, P. Hacek, J. Havlicek, A. Havranek, J. Horacek, M. Hron, M. Imrisek, M. Komm, K. Kovarik, J. Krbec, T. Markovic, E. Matveeva, K. Mitosinkova, J. Mlynar, D. Naydenkova, R. Panek, R. Paprok, M. Peterka, A. Podolnik, J. Seidl, M. Sos, J. Stöckel, M. Tomes, M. Varavin, J. Varju, M. Vlainic, P. Vondracek, J. Zajac, F. Zacek, M. Stano, G. Anda, D. Dunai, T. Krizsanoczi, D. Refy, S. Zoletnik, A. Silva, R. Gomes, T. Pereira, Tsv. Popov, D. Sarychev, G.P. Ermak, J. Zebrowski, M. Jakubowski, M. Rabinski, K. Malinowski, S. Nanobashvili, M. Spolaore, N. Vianello, E. Gauthier, J.P. Gunn, A. Devitre, J. Instrum. 12, C12015 (2017)

115. O. Grover, J. Adámek, J. Seidl, A. Devitre, M. Sos, P. Vondracek, P. Bilkova, M. Hron, Rev. Sci. Instrum. 88, 063501 (2017)

116. J. Adámek, J. Seidl, J. Horacek, M. Komm, T. Eich, R. Panek, J. Cavalier, A. Devitre, M. Peterka, P. Vondracek, J. Stöckel, D. Sestak, O. Grover, P. Bilkova, P. Böhm, J. Varju, A. Havranek, V. Weinzettl, J. Lovell, M. Dimitrova, K. Mitosinkova, R. Dejarnac, M. Hron, Nucl. Fusion 57, 116017 (2017)

117. J. Adámek, J. Seidl, M. Komm, V. Weinzettl, R. Panek, J. Stöckel, M. Hron, P. Hacek, M. Imrisek, P. Vondracek, J. Horacek, A. Devitre, Nucl. Fusion 57, 022010 (2017)

118. M. Čada, Z. Hubička, P. Adámek, J. Olejníček, Š. Kment, J. Adámek, J. Stöckel, Rev. Sci. Instrum. 86, 073510 (2015)

119. V.I. Demidov, S.V. Ratynskaia, K. Rypdal, Rev. Sci. Instrum. 73, 3409 (2002)

120. S.V. Ratynskaia, V.I. Demidov, K. Rypdal, Rev. Sci. Instrum. 71, 1367 (2000)

121. V.I. Demidov, S.M. Finnegan, M.E. Koepke, E.W. Reynolds, Rev. Sci. Instrum. 74, 4558 (2003)

122. V.I. Demidov, S.M. Finnegan, M.E. Koepke, E.W. Reynolds, Contrib. Plasma Phys. 44, 689 (2004)

123. M.E. Koepke, V.I. Demidov, S.M. Finnegan, E.W. Reynolds, Contrib. Plasma Phys. 46, 385 (2006)

124. V.I. Demidov, M.E. Koepke, Y. Raitses, Rev. Sci. Instrum. 81, 10E129 (2010)

125. S. Costea, Experimental and numerical investigations of electric probes and blobs in magnetically-confined fusion plasmas, Ph.D. thesis, University of Innsbruck, 2018 